\title{
A methodological framework for the implementation of circular economy thinking in higher education institutions: Towards sustainable campus management
}

DOI:

10.1016/j.jclepro.2019.04.060

\section{Document Version \\ Accepted author manuscript}

Link to publication record in Manchester Research Explorer

Citation for published version (APA):

Mendoza, J. M. F., Gallego-schmid, A., \& Azapagic, A. (2019). A methodological framework for the implementation of circular economy thinking in higher education institutions: Towards sustainable campus management. Journal of Cleaner Production, 226, 831-844. https://doi.org/10.1016/j.jclepro.2019.04.060

Published in:

Journal of Cleaner Production

\section{Citing this paper}

Please note that where the full-text provided on Manchester Research Explorer is the Author Accepted Manuscript or Proof version this may differ from the final Published version. If citing, it is advised that you check and use the publisher's definitive version.

\section{General rights}

Copyright and moral rights for the publications made accessible in the Research Explorer are retained by the authors and/or other copyright owners and it is a condition of accessing publications that users recognise and abide by the legal requirements associated with these rights.

\section{Takedown policy}

If you believe that this document breaches copyright please refer to the University of Manchester's Takedown Procedures [http://man.ac.uk/04Y6Bo] or contact uml.scholarlycommunications@manchester.ac.uk providing relevant details, so we can investigate your claim.

\section{OPEN ACCESS}




\title{
A methodological framework for the implementation of circular economy thinking in higher education institutions: Towards sustainable campus management
}

\author{
Joan Manuel F. Mendoza ${ }^{\mathrm{a}, \star}$, Alejandro Gallego-Schmid ${ }^{\mathrm{a}, \mathrm{b}}$ and Adisa Azapagic ${ }^{\mathrm{a}}$ \\ ${ }^{a}$ Sustainable Industrial Systems, School of Chemical Engineering and Analytical Science, The Mill, \\ The University of Manchester, Sackville Street, M13 9PL, Manchester, United Kingdom. \\ ${ }^{b}$ Tyndall Centre for Climate Change Research, School of Mechanical, Aerospace and Civil \\ Engineering, The University of Manchester, Pariser Building, Sackville Street, Manchester M13 \\ 9PL, UK.
}

Corresponding author $\left(^{\star}\right)$ : joan.mendoza@manchester.ac.uk; joanmanuel.fm@gmail.com.

Keywords: Corporate sustainability; resource efficiency; social responsibility; stakeholder engagement; sustainable campus management.

\begin{abstract}
Many higher education institutions have started to develop academic curricula, research capacity and outreach activities related to circular economy. However, little is known yet on how to apply circular economy thinking to sustainable campus management. In an attempt to address this gap, this paper proposes a methodological framework and guidance to help universities develop a circular economy strategy aimed at improving resource efficiency and environmental sustainability of their campus operations. The approach is compatible with sustainability management frameworks as it follows the well-known iterative process of planning, doing, checking and improving. The framework involves three main steps: analysis of current situation with respect to circular economy within the organisation; stakeholder engagement to get a buy-in and inform the development of a circular economy strategy; and implementation of the strategy following the guidelines provided within the framework. Application of the framework is illustrated through a case of the University of Manchester, demonstrating how circular economy principles can be used to benchmark existing sustainability policies and action plans. The paper also shows how engaging key stakeholders can be used to identify challenges and opportunities for embedding circular economy thinking into the university's sustainability management systems. The proposed framework and the guidelines for implementation of circular economy thinking are generic and can be applied by any institution across the higher education sector.
\end{abstract}

\section{Introduction}

A circular economy (CE) is predicated on the reuse of materials and products for the longest possible time in closed-loop biological and technical systems in order to boost resource productivity and system sustainability (EMF 2015a, EEA 2016). Thus, many cities (Prendeville et al. 2017), regions (Ihobe 2016) and countries (McDowall et al. 2017) are actively encouraging deployment of a CE as an instrumental pathway towards sustainable development (Geissdoerfer et al. 2017). This implies the development of a combination of technological, organisational and social innovations within and across stakeholder-value networks (Boons and Lüdeke-Freund 2013).

There is strong link between CE and sustainability (Sauvé et al. 2016; Murray et al. 2017; Geisendorf and Pietrulla 2017), with the former representing a condition and strategic pathway to achieving the latter (Bocken et al. 2014, Geissdoerfer et al. 2017). A CE does not rest simply on marginal improvements in the efficiency and environmental performance of linear production and consumption systems, but requires rethinking of the way products and services, supply chains, stakeholder networks and businesses models are designed and operated (Young and Tilley 2006, Braungart et al. 2006, Barbiroli 2006). If implemented properly to avoid burden shifting and the rebound effect (Zink and Geyer 2017; Vivanco et al. 2018), CE can provide a powerful framework for radical improvements in resource efficiency and related sustainability performance of organisations (Ghisellini et al. 2016).

However, the uptake of the CE concept by organisations is still very limited (Bocken et al. 2017) and little is known about the practical implementation of CE thinking in corporate sustainability 
management. In an attempt to support CE practice at different levels and scales, various methods are beginning to emerge (Mendoza et al. 2017). For instance, Antikainen and Valkokari (2016) have developed a framework for sustainable circular business model innovation based on the analysis of a business ecosystem, the perception of value to stakeholders and the associated circularity and sustainability costs and benefits. Another example is a circular business model canvas (Lewandowski 2016) aimed at accelerating a transition of a company to a CE. Furthermore, a collaborative CE framework has been suggested for the development of sustainable business models through engagement of procurers and suppliers (Witjes and Lozano 2016). Moreover, Kraaijenhagen et al. (2016) describe a ten-step process to initiate CE projects within an organisation, including the engagement of strategic collaboration partners and the identification of financial and non-financial incentives. These CE frameworks can support the identification, evaluation and implementation of "circular" and sustainable solutions to a greater or lesser extent. However, these frameworks are in an early stage of development (Elia et al. 2017) and their reallife application in daily practice has scarcely been investigated in the literature (Heyes et al. 2018). Case studies demonstrating how these frameworks can drive change within organisations in different sectors are even more scant. Thus, practical guidance on CE strategy implementation remains vague (Pauliuk 2018).

One area of particular interest for exploration due to its strategic role in supporting sustainable development is the higher education (HE) sector. According to the OECD (2010), Higher Education Institutions (HEls) are major drivers of economic growth and social wellbeing through knowledge creation (research), knowledge transfer (teaching) and community development (outreach activities). A successful mobilisation of resources from HEls can have a significant positive effect on local economies, including the achievement of regional socio-economic strategies (EU 2011). However, HEls are also significant consumers of resources and sources of waste and environmental impacts. In the UK, the annual energy costs for colleges and universities are around $£ 400 \mathrm{M}$, resulting in 3.1 Mt of greenhouse gas (GHG) emissions (Carbon Trust 2012). The former is equivalent to the net annual average earnings of around 26,000 single people in the European Union (EU) (Eurostat 2018a), whereas the latter equals the annual GHG emissions by more than $1,550,000$ average EU households (EEA 2014). Likewise, over $322 \mathrm{kt} / \mathrm{year}$ of waste is disposed into landfills by HEls in the UK (EAUC 2016). This is equivalent to the annual municipal waste generation by around 692,000 people in the EU (Eurostat 2018b). These values would be even higher if resource consumption and impacts of outreach activities were included. Accordingly, the scientific literature has focused on finding ways to improve sustainability management in HEls to help reduce their environmental footprint (Ferrer-Balas et al. 2010; Ramos et al. 2015). However, little is known yet about the implementation of CE thinking in HEls as a mechanism for an efficient use of resources and improved sustainability performance.

To facilitate this, several HEls worldwide have joined the Ellen MacArthur Foundation (EMF) with the purpose of building academic curricula, research capacity and collaborative ventures based on the CE philosophy (EMF 2015b; EMF 2015c). As a result, they have started to develop master degrees, courses and webinars to gain a better understanding of the CE principles, application and benefits (EMF 2015d). Innovative educative approaches to develop CE-related teaching programmes have been proposed by Three C (2014), Kilkiş (2017), Gallego-Schmid et al. (2018) and Whalen et al. (2018). In parallel, HEls have started to develop CE-oriented research projects responding to the challenges of making the CE mainstream. A review of some of these CE research activities can be found in Ghisellini et al. (2016), Lieder and Rashid (2016), Masi et al. (2017), Mendoza et al. (2017) and Winans et al. (2018).

However, there is a lack of knowledge on how to implement CE principles to sustainable campus management (Kopnina 2018). As far as we are aware, only one study has analysed the implementation of a CE to campus operation (University of Edinburgh 2015) suggesting that a range of $C E$ activities are taking place within the university, even if they are not currently recorded as such. Examples include the WARP-it re-use online portal (2017) for staff to exchange unwanted items and the student-led Swap and Re-use Hub (2017) to promote smarter and more sustainable ways of meeting peoples' material needs. However, the University found a number of challenges that should be overcome to embed CE thinking across the organisation, including an overall lack of 
awareness and understanding of its meaning and benefits, conservative governance structures, operating models and mindsets, insufficient policies, guidelines, collaboration and frameworks, as well as time and financial constraints.

Although the above study provides relevant insights, there is still a lack of information about the process by which organisational and operational change towards a CE can take place. Thus, there is a need for further studies examining barriers and opportunities for CE implementation in HEls and the whole HE sector. There is also a need for practical frameworks able to support the process of CE implementation step by step. In an attempt to address this need, this paper proposes such a framework and explores its potential for integrating CE thinking into sustainability management systems in HEls. An application of the framework is illustrated through the case of the University of Manchester (UoM), the UK's largest single-campus university (UoM 2017a). The key novelties of this paper include a new CE framework tailored for HEls and aimed at sustainable campus management and ii) a practical case study demonstrating how HEls can start driving change towards a CE, which is the ultimate goal of this research. The framework is generic and flexible enough to be applied to any type of HEI, regardless of its size and location.

The rest of the paper is organised as follows. Section 2 discusses the proposed framework, followed in Section 3 by an illustration of how it can be applied in practice, including the guidance on the needed strategic and operational change. A critical assessment of the research outcomes and a discussion of the limitations of the proposed framework are provided in Section 4. Finally, the conclusions and recommendations for further research are given in Section 5.

\section{Methodology}

The proposed framework tailored for HEls consists of three main steps (Figure 1):

A) background analysis (baseline information gathering);

B) foreground analysis (stakeholder engagement); and

C) implementation of a CE strategy (guidelines for action).

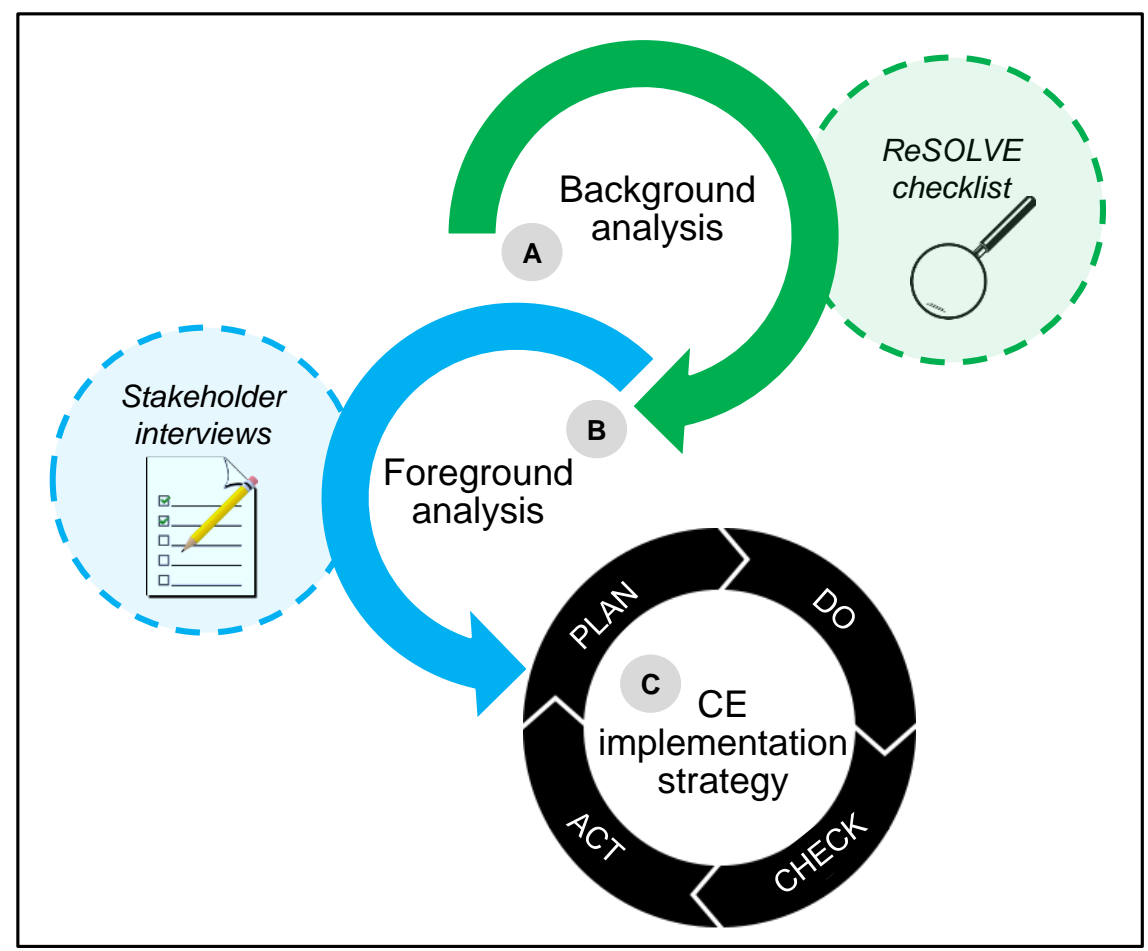

Figure $1 \mathrm{~A}$ framework for facilitating the implementation of a CE in higher education institutions (CE: Circular Economy; ReSOLVE: Regenerate, Share, Optimise, Loop, Virtualise, Exchange). 
The background analysis $(A)$ is important for gathering baseline information and determining the scope of the sustainability policies and practices implemented by an $\mathrm{HEl}$. This in turn enables strategic examination of opportunities to drive change towards a CE. The latter will depend crucially on the buy-in from the sustainability-related and other stakeholders within the organisation, which is facilitated through a foreground analysis (B). This step is aimed at gathering detailed information on the effectiveness of the sustainability decision-making processes within the $\mathrm{HEI}$ to help determine the current level of implementation of CE thinking. This information is then used to identify intervention areas and define guidelines for the development of a CE implementation strategy in the final, implementation step $(\mathrm{C})$. Following the iterative plan-do-checkadjust (PDCA) approach for continuous improvement of organisational management (Deming spiral), the background and foreground analyses can be considered as the planning step, whereas CE implementation strategy involves doing, checking and adjusting (Figure 1).

It is important to emphasise that this framework is similar in nature to other methods used by HEls to drive change towards sustainability (see a review of methods in Ferrer-Balas et al. (2010), Ramos et al. (2015) and Amaral et al. (2015)). For instance, the steps described above fit within the managerial method for a sustainable university model proposed by Velazquez et al. (2006) and Lukman and Glavic (2007). These steps also resonate with the stakeholder engagement process suggested by Too and Bajracharya (2015) for development of a sustainable campus. However, most of these methods are aimed at supporting the implementation of linear eco-efficiency solutions (e.g. reduction in energy consumption and GHG emissions) rather than facilitating the implementation of innovative solutions for improved resource efficiency and sustainability performance of campus operations. Therefore, the main distinguishing feature of the framework proposed here is that it is underpinned by CE thinking as a prerequisite for improved resource efficiency and sustainable campus management. As far as the authors are aware, this has not yet been addressed in the literature related to sustainability management in HEls.

Each of the three steps in the framework is described briefly below, followed by a further detailed discussion in Section 3.

\subsection{Step A: Background analysis}

A background analysis is performed to evaluate if (and how) CE thinking is currently integrated within the corporate sustainability policies of an $\mathrm{HEl}$. These can include resource, environmental and social policies as well as strategic plans for the future. The purpose of this analysis is to get an overview of the organisation's awareness, knowledge and capabilities related to CE and sustainability management.

The congruence of each policy with the CE principles is analysed by using the ReSOLVE checklist proposed by the Ellen McArthur Foundation (EMF 2015a). This checklist integrates six synergistic actions - regenerate, share, optimise, loop, virtualise and exchange - with a number of underpinning requirements that can support implementation of a CE. The ReSOLVE actions comply with and translate into the CE principles of i) preserving and enhancing natural capital by controlling finite stocks and balancing renewable resource flows; ii) optimising resource yields by circulating products, components, and materials at the highest utility and value at all times within technical and biological cycles; and iii) fostering system effectiveness by revealing and designing out negative externalities (EMF 2015a). Thus, ReSOLVE represents a simple but practical tool for analysing the scope of HEl's current sustainability practices against the CE principles and actions. It also provides insights for the development of CE strategies in different areas (research, teaching and outreach). The use of the ReSOLVE checklist has already been demonstrated in other sectors and applications but not in the HE sector yet. For example, it has been used to assess CE policy intervention areas at a country level (EMF 2015), explore practical applications of CE principles in the built environment and in cities (Arup 2016; Prendeville et al. 2017) and identify alternative product-service solutions in the ICT sector (Heyes et al. 2018). Thus, ReSOLVE is a practical tool for supporting CE analytical processes, including the assessment of the scope of sustainability policies as demonstrated in Section 3.1. 


\subsection{Step B: Foreground analysis}

This step aims to engage sustainability-related stakeholders and decision-makers within the HEl. The aim is to learn about the effectiveness of the mechanisms employed by the organisation for identifying, evaluating and monitoring the implementation of sustainability strategies. A further aim is to identify challenges and opportunities for integrating CE thinking within the sustainability management processes. Hence, at this stage external stakeholders are not considered but their involvement becomes important during the implementation stage.

Internal stakeholders can be engaged in many different ways, including interviews, focus groups, workshops and surveys (Camilleri 2015). In this work, semi-structured interviews have been used as a vehicle for stakeholder engagement. These interviews can be conducted by using a predefined interview protocol, questionnaire or a simple list of subjects for discussion, flexible enough to allow interviewees to respond in the order and manner they choose (Reed et al. 2009). For the purposes of this research, a questionnaire consisting of ten open-ended questions was developed and used to interview the stakeholders, following the approach proposed by Hallstedt et al. (2010). The purpose of the questions was to screen the criteria, methods, tools and indicators used by the stakeholders in supporting sustainability management processes. The questionnaire was structured into three main parts: corporate strategy assessment, organisational management and improvement opportunities (see Section S1 in the Supporting Information (SI)). The first two questions were aimed at getting an overview of the stakeholders' know-how of CE and sustainability implementation within the organisation. If stakeholders were not entirely familiar with the CE concept and principles, they were briefly described by the researchers during the interview using resources from EMF (2015a) (e.g. the butterfly diagram, including the CE principles and ReSOLVE actions). This ensured all the stakeholders would have a common understanding of the concept and its principles before asking more specific questions. The subsequent seven questions were aimed at obtaining information on the effectiveness of the current decision-support mechanisms used by senior managers and operational staff to manage organisational sustainability. This included the analysis of their capability to guide and drive top-down and bottomup change. Finally, the last question asked the stakeholders to propose solutions for embedding CE thinking into the current sustainability management mechanisms.

The questionnaire was sent to the stakeholders by e-mail prior to the interviews to familiarise themselves with the questions. They were interviewed at their premises and the interviews lasted 1-1.5 h. The interviews were anonymised, which facilitated openness, frankness and willingness of interviewees to share information and opinions. The interviews were recorded by audio devices and immediately transcribed to minimise the potential for mixing up the information between the interviews or the effect of imperfect memory (Bocken 2015). Audio recordings and interview transcriptions also helped to avoid any potential subjectivity by the researchers in the analysis of the outcomes. The outcomes from the interviews were analysed per topic-question according to the stakeholders' know-how and role in organisational sustainability management. This ensured that the findings reflected multiple observations rather than a single opinion. The outcomes of the interviews are discussed in Section 3.2.

\subsection{Step C: Circular economy implementation strategy}

In the final step of the framework, the outputs from steps $A$ and B are used to develop a CE implementation strategy. This involves identification of barriers and opportunities and development of practical guidance or a checklist for implementation of a CE strategy. To ease the implementation, CE thinking should be embedded within the existing environmental or sustainability management frameworks used by the $\mathrm{HEl}$. Therefore, this step follows the guidelines in Azapagic (2003), ISO 14001 (ISO 2015) and BS 8001 (BSI 2017). Azapagic provides a step-bystep guidance for implementation of a sustainability strategy into the organisation's existing environmental management system while ISO 14001 sets out the requirements for a holistic environmental management system. BS 8001 focuses specifically on CE to help organisations implement its principles in practice by following an eight-step framework and using the criteria consistent with those in Azapagic (2003) and ISO 14001 (ISO 2015). Based on the management criteria specified in these sources (Table $\mathrm{S} 1$ in the $\mathrm{SI}$ ), a generic checklist has been developed to 
guide CE implementation strategy in HEls. As shown in Table 1, the checklist involves eight steps discussed below.

1. Build a corporate vision: Developing a vision compliant with the CE principles and coherent with the organisation's core goals and priorities is crucial to capture fully the sustainability potential of pursuing a CE. Such a vision will help define the direction and scope of the HEl's future activities and guide strategic decision-making processes to build successful circular (resource efficient) and sustainable corporate strategies (Mendoza et al. 2017).

2. Create a leadership team: Strong leadership and commitment to CE is essential to ensuring it will be embedded into all the functional areas within the HEI. A CE-committed leadership team, consisting of senior managers and operational staff, should be formed to drive change effectively, both top-down and bottom-up. The team should be able to resolve competing organisational goals, strategic priorities and divergent demands, while keeping the organisation focused on the pathway towards a CE. The leadership team should also be responsible for building reputation and trust of employees and external stakeholders in terms of organisational CE and sustainability management (Azapagic 2003).

3. Perform a framing and scoping study: The leadership team should acquire the necessary resources to perform a framing and scoping study to determine the relevance of the CE to the organisation and identify potential intervention areas, including risks, barriers and opportunities, to start driving the needed change (BSI 2017). Such study involves the development of different tasks, as described in Table 1. Stakeholder mapping is particularly important to identify internal and external actors of relevance to the HEI. The latter are particularly important for the development and implementation of CE actions which cannot be achieved by individual HEls alone.

4. Develop an action plan: Building on the findings from the framing and scoping study, an action plan for the development of a CE implementation strategy should be devised. Action plans, including roadmaps, milestones, performance metrics and responsibilities, are important to address both risks and opportunities for realising a long-term vision and strategic goals (ISO 2015). The action plan should also suggest the use of effective tools for analysing and validating the suitability and feasibility of CE strategies relevant to the organisation. Existing CE frameworks (for a review, see e.g. Mendoza et al. 2017) may prove useful in helping HEls develop and monitor the implementation of a CE strategy. Likewise, current data collection systems could be modified and used to monitor CE implementation in HEls (University of Edinburgh 2015).

5. Build a business case and strategy: The execution of the action plan should be able to help build a business case for the development of a CE implementation strategy to transition the $\mathrm{HEl}$ to a more circular and sustainable organisation. A business case is required to demonstrate the benefits of implementing priority CE actions across the university campus. It would also help gain commitment and buy-in from senior managers and operational staff and secure the necessary resources to pilot, roll-out and scale-up CE solutions (BSI 2017). Furthermore, it would lead to the development of a comprehensive CE strategy implementation and management system.

6. Communicate and execute the strategy: Once developed, the CE strategy should be communicated and executed across the HEl. Effective communication is essential for promoting the concept of CE as well as for promoting the organisation's achievements. It entails the development of meaningful internal and external reporting procedures, outlining the organisation's CE and sustainability management goals and the resulting benefits (Azapagic 2003). Likewise, top managers need to assign relevant responsibilities for the effective execution and monitoring of the CE strategy.

7. Monitor and report progress: The organisation should determine what success would look like in the future and how this is to be measured over time. This requires an agreement on 
meaningful KPIs to monitor progress and improve the CE strategy periodically. It is worth noting that no unique method or metrics is likely to fully capture the circularity performance of an organisation or enable benchmarking between different HEls due to the challenge of considering environmental, social and economic factors (BSI 2017). Thus, HEls should use those metrics and reporting systems that would be able to measure and demonstrate progress related to the CE vision and goals described in the CE strategy.

8. Revise and improve strategy: Building on the knowledge and expertise gained by the HEI through the implementation of the CE strategy over time, the CE vision, action plan, business case, stakeholder engagement systems, metrics and communication mechanisms should be revised and improved to ensure the $\mathrm{HEI}$ is heading in the right direction.

Table 1 Guidance checklist for integrating CE thinking in sustainability management processes in HEls.

\begin{tabular}{|c|c|}
\hline Key steps & Organisational and operational requirements \\
\hline 1. Build a corporate vision & $\begin{array}{l}\text { - } \quad \text { Define an overarching strategic vision congruent with CE principles } \\
\text { - } \quad \text { Analyse drivers and constraints } \\
\text { - } \quad \text { Agree on the CE vision and a high-level strategy }\end{array}$ \\
\hline $\begin{array}{l}\text { 2. Create a leadership } \\
\text { team }\end{array}$ & $\begin{array}{ll}- & \text { Identify and engage relevant stakeholders } \\
\text { - } & \text { Define organisational roles, skills and responsibilities } \\
\text { - } & \text { Ensure leadership commitment, internal awareness and enthusiasm to CE }\end{array}$ \\
\hline $\begin{array}{l}\text { 3. Perform a framing and } \\
\text { scoping study }\end{array}$ & $\begin{array}{ll} & \text { Assess the organisation's baseline performance against CE } \\
\text { - } & \text { Identify the organisation's needs and stakeholder expectations } \\
\text { - } & \text { Determine the scope of a CE management system }\end{array}$ \\
\hline 4. Develop an action plan & $\begin{array}{ll}\text { - } & \text { Set objectives and targets for exploration } \\
\text { - } & \text { Identify and allocate resources and competences } \\
\text { - } & \text { Select appropriate tools to assess opportunities to drive change } \\
\text { - } & \text { Devise and assess the feasibility of organisational and operational CE } \\
& \text { solutions }\end{array}$ \\
\hline $\begin{array}{l}\text { 5. Build a business case } \\
\text { and strategy }\end{array}$ & $\begin{array}{ll}\text { - } & \text { Build a scaled-up CE strategy with a roadmap } \\
\text { - } & \text { Set priority actions aligned with the corporate core goals } \\
\text { - } & \text { Secure top-level ownership, buy-in and governance } \\
\end{array}$ \\
\hline $\begin{array}{l}\text { 6. Communicate and } \\
\text { execute the strategy }\end{array}$ & $\begin{array}{ll} & \text { Develop projects to put the CE strategy into practice } \\
\text { - } & \text { Raise awareness and train staff on CE management } \\
\text { - } & \text { Communicate the CE strategy internally and externally }\end{array}$ \\
\hline $\begin{array}{l}\text { 7. Monitor and report } \\
\text { progress against the } \\
\text { strategy }\end{array}$ & $\begin{array}{l}\text { - } \quad \text { Set mechanisms and indicators to measure CE progress over time } \\
\text { - } \quad \text { Integrate CE metrics within sustainability reporting systems } \\
\text { - } \quad \text { Facilitate continual and transformational improvement }\end{array}$ \\
\hline $\begin{array}{l}\text { 8. Revise and improve the } \\
\text { strategy }\end{array}$ & $\begin{array}{l}\text { - } \quad \text { Run internal audits and management review processes } \\
\text { - } \quad \text { Take corrective action for continuous improvement }\end{array}$ \\
\hline
\end{tabular}

\section{Application of the framework: A case study}

The application of the above framework is illustrated by a case study of the University of Manchester. As the university is still at the early stages of considering $\mathrm{CE}$, it is not possible to demonstrate the implementation of CE thinking; hence, the focus in this section is on the first two steps of the framework.

The University houses over 27,000 undergraduates and almost 12,000 postgraduates across three faculties. With more than 12,000 staff, it is one of the largest employers in Greater Manchester (UoM 2017a). It spreads over an estate comprising 245 buildings occupying over 890 acres of land (UoM 2017b). It is also currently transforming its campus and the surrounding area with a total investment of $£ 1$ billion. This represents the largest-ever estates investment by a UK university (UoM 2015). Therefore, the organisation has a major socio-economic influence on the region. However, it also consumes significant resources and generates various environmental impacts. In 2015/16, the university consumed almost 247 GWh of energy, emitting around 72,200 t of GHG (UoM 2017c). The latter is equivalent to annual GHG emissions by around 36,000 average EU households (EEA 2014). The organisation also used over $742,000 \mathrm{~m}^{3}$ of water annually, enough to fill 280 Olympic swimming pools. Furthermore, $6700 \mathrm{t}$ of waste was generated, of which only 
around 30\% was recycled (UoM 2017d). Consequently, embedding CE thinking within decisionmaking processes would help the university to improve resource efficiency and reduce environmental impacts.

\subsection{Step A: Background analysis}

The background analysis involved a review of the university's policies and action plans relevant to sustainability as well as their scope with regard to circular economy.

\subsubsection{Sustainability-related policies and action plans}

The following university policies and action are relevant to sustainability:

- Manchester 2020 Strategic Plan (UoM 2015);

- Campus Masterplan 2012-2022 (UoM 2012);

- Environmental Sustainability Strategy (UoM 2016);

- Sustainable Resources Plan (UoM 2017c); and

- Living Campus Plan (UoM 2017e).

Figure 2 provides an overview of the hierarchical relationship between the university's sustainability policies and action plans. The Manchester 2020 Strategic Plan (UoM 2015) is the key policy because it describes the core goals, strategic priorities and high-level key performance indicators (KPI). The core goals of the organisation are: 1) to develop world-class research; 2) to provide an outstanding teaching and student experience; and 3) to excel in social responsibility. With respect to the last goal, the university has committed to pursuing change across five priorities: research with impact, socially-responsible graduates, community engagement, responsible processes and environmental sustainability. Accordingly, the environmental sustainability strategy (UoM 2016) specifies four key objectives, each set within the overall approach to social responsibility:

- to apply sustainability-oriented research on its own campus and across Greater Manchester, as well as to minimise the environmental impact of carrying it out;

- to embed sustainability as a key theme across teaching and the wider student experience, using the campus as a living laboratory for sustainability practice;

- to engage with staff, students and alumni and partner with organisations in pursuit of shared sustainability goals; and

- to ensure the organisational processes are resource and cost effective and that they contribute to creating an environment that enhances health and wellbeing.

These environmental sustainability objectives are delivered through two core action plans: the Sustainable Resources Plan (SRP) and the Living Campus Plan (LCP). The SRP (UoM 2017c) describes a range of targets and actions to reduce resource consumption and environmental impacts from the university's operations. Ten delivery areas have been identified to put the plan into practice (Table 2). Targets have been set for 2022, consistent with the time scale of the Campus Masterplan (UoM 2012). The LCP (UoM 2017e) draws on the relationship between the natural environment, biodiversity, health and wellbeing (Table 2). This plan was developed to improve the quality, function and scale of green infrastructure across campus as well as designing healthy spaces resilient to climate change.

The "10,000 Actions" signature programme (UoM 2017f) was launched to facilitate the operationalisation of the SRP and LCP by providing all 10,000+ staff an opportunity to engage in sustainability practice through responsible purchasing, travel, living campus, energy, waste and water. This programme is the UK's largest environmental sustainability initiative for staff in higher education (UoM 2017f). The university also takes part in the national environmental accreditation scheme Green Impact (NUS 2017), which is a behavioural change programme that empowers students and staff to make meaningful and positive changes towards the environmental sustainability. Sustainability Champions (network of individuals) also lead positive change for sustainability in their areas of influence (UoM 2017g). 


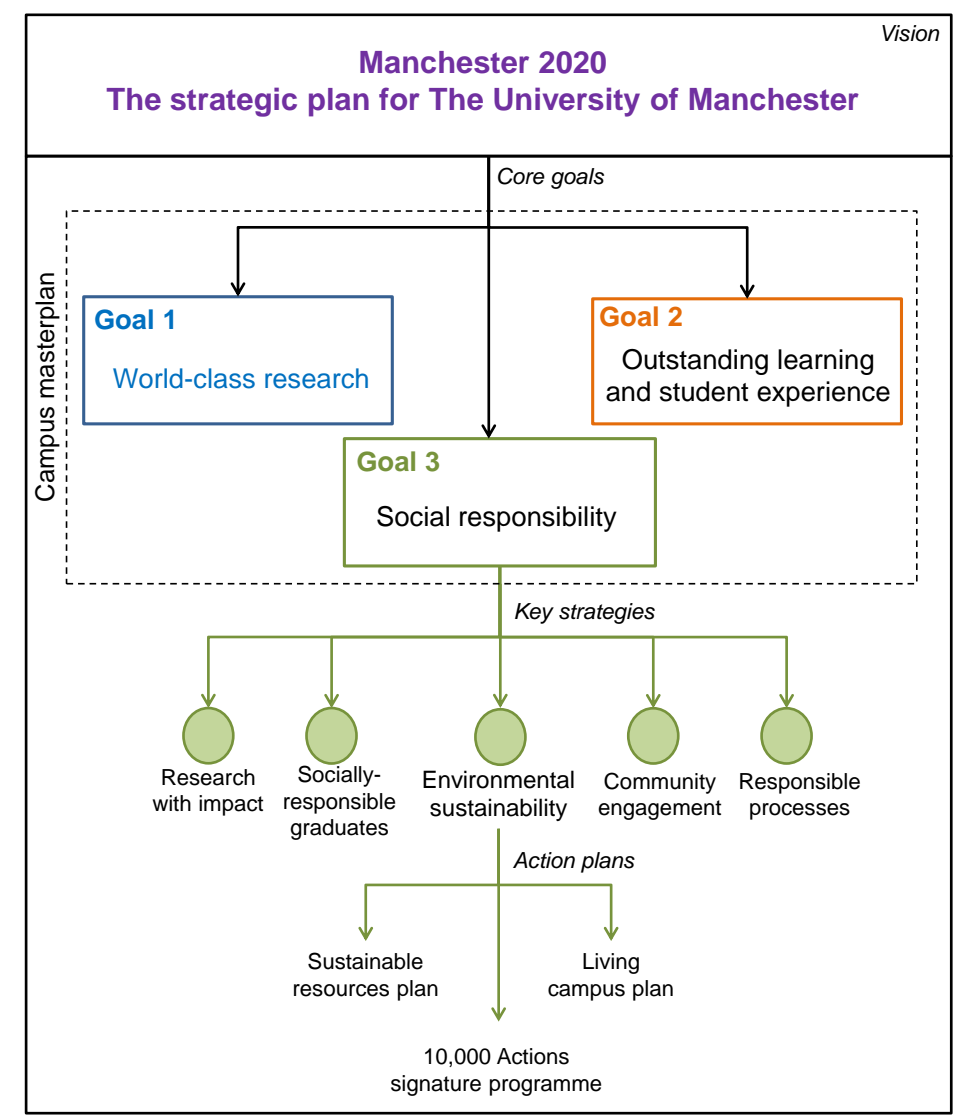

Figure 2 Hierarchical relationship between the sustainability policies and action plans of the University of Manchester.

One of the most important enabling strategies for achieving the three core goals of the university, including the environmental sustainability, is the development of a world-class estate through the implementation of the Campus Masterplan (UoM 2012). The latter is a ten-year capital investment plan ( 11 billion) to develop a sustainable urban university. This includes the construction of new buildings and facilities, as well as refurbishment of the existing building stock and public realm.

These corporate policies demonstrate that the UoM is committed to sustainability. However, there is neither explicit reference to the CE concept nor a mention of its strategic value to support organisational sustainability management. This suggests that the CE concept has not been yet addressed and internalised by the university. However, this does not mean that current sustainability strategies implemented by the organisation do not integrate CE principles, as demonstrated in the following section.

\subsubsection{Scope of sustainability policies with regard to circular economy}

Table 2 provides an overview of the scope of the two most relevant environmental sustainability plans implemented by the UoM: Sustainable Resources Plan and the Living Campus Plan. For further details on the topic areas, baseline values of the indicators and 2022 targets, see Table S3 in the SI. Table 2 indicates whether and how these strategies are related to a particular ReSOLVE action and whether they facilitate (primary effect) and/or reinforce implementation of the other ReSOLVE actions (secondary effect). A comprehensive analysis of the contribution of the university's environmental sustainability strategies to the ReSOLVE actions and the definition of the latter are provided in Section S2 in the SI.

It can be seen from Table 2 that, although there is no mention of the CE concept in the university's sustainability policies, the CE principles are applied in certain delivery areas. Waste reduction and sustainable catering represent the best examples because they implement four of the five ReSOLVE actions and some reinforce other actions. For example, the furniture-for-reuse store does not only facilitate product sharing but also contributes to optimising the system's performance 
and resource flows because the furniture that cannot be reused is sent to recycling. However, many of the university's environmental sustainability actions are limited in scope and they mostly focus on reducing resource consumption, waste generation and carbon emissions rather than rethinking current processes and reorienting sustainability strategies. For instance, the Environmental Sustainability Strategy (UoM 2016) and the Sustainable Resources Plan (UoM 2017c) do not mention the value of using renewable energy to minimise the environmental impacts related to energy consumption. Improvements in energy efficiency are important to reduce the dependence on fossil fuels and negative externalities. However they are not sufficient to support long-term sustainability. As suggested by EMF (2015a), systems should ultimately aim to run on renewable energy. Thus, the university should set renewable energy goals along with energy reduction targets. Likewise, water efficiency strategies should be complemented with innovative solutions for circular water management. According to IWA (2016), closed-loop water systems should be developed with cascading water quality options determined and differentiated by use. Some circular water management strategies in the university context include rainwater harvesting, grey water recycling for non-potable reuse and direct potable reuse (IWA 2016). However, none of these strategies is mentioned in the university's sustainability policies and action plans.

A further example is the university's delivery plan for sustainable construction, which focuses on the BREEAM criteria (BRE 2017). These are not stringent enough to drive a significant change in the sustainability (and circularity) performance of constructed assets because they do not take a full life cycle perspective (Kudryashova et al. 2015). This also applies to the environmental sustainability project trackers developed by the university. The UK Green Building Council's (2017) guide on embedding CE thinking into construction projects and the Level(s) framework (JRC 2017) for measuring the life cycle circularity and sustainability performance of buildings can provide useful insights for integration of CE principles in construction projects.

Although the university has achieved Level 5 of the implementation of the Flexible Framework (DEFRA 2011) for embedding sustainability criteria into key areas of procurement, there is no evidence that it is applying CE criteria to support it. According to ING (2015), procurement strategies for CE should include an assessment of the total life cycle cost of ownership, assess the circularity of suppliers, develop a circular procurement plan and use suppliers that can deliver circular product-service systems. The university's procurement team should pursue these procedures as part of sustainable procurement. The NETpositive approach (and supplier engagement tool; see Section 3.2.2.1) to responsible procurement to reduce not only the negative impacts (e.g. carbon emissions) but also to enhance positive benefits (e.g. social progress) (UoM 2017h) could be extended further by applying CE criteria.

Finally, only a few environmental sustainability actions have a primary effect on the virtualise (dematerialisation) and exchange (redesigning processes) ReSOLVE actions. There is no evidence that the university is looking for opportunities to dematerialise fully its campus operations by acquiring services rather than purchasing products as a general rule. Rather than purchasing new equipment, the organisation could benefit from access to performance, functionality or capability through leasing or pay-per-use contracts (Accenture 2015; Bocken et al. 2016). Although such models can be cost-prohibitive, the large size of the organisation means that better deals could be available for 'bulk' supply of services. Likewise, a greater use of digital technologies (e.g. sensors and smart monitoring devices) could facilitate better asset control and preventive maintenance, enabling product-life extension and dematerialisation (Accenture 2017). Likewise, the ability to monitor and manage physical objects digitally may lead to the development of innovative and successful CE models (McKinsey 2015). Nevertheless, there is no evidence that the organisation is looking to redesign its organisational processes by applying CE thinking.

These findings demonstrate the importance of identifying opportunities to reinforce and extend the scope of the university's environmental sustainability strategies and actions in order to maximise the circularity and sustainability performance of the organisation. In this process, it is essential to evaluate the strengths, barriers and challenges associated with the sustainability management mechanisms used within the university in order to identify appropriate ways for integrating strategic and operational CE thinking, as discussed in the next section. 
Table 2 Scope of the Sustainable Resources Plan (SRP) and the Living Campus Plan (LCP) against CE principles and actions.

\begin{tabular}{|c|c|c|c|c|c|c|c|c|}
\hline \multirow[t]{2}{*}{ Plans } & \multirow[t]{2}{*}{ Delivery area } & \multirow[t]{2}{*}{ Actions and programmes } & \multicolumn{6}{|c|}{ ReSOLVE checklist $^{a}$} \\
\hline & & & $\underset{1-3}{\mathbf{R e}}$ & $\underset{2,3}{\mathbf{S}}$ & $\begin{array}{l}\mathbf{O} \\
2,3\end{array}$ & $\mathrm{~L}$ & $\begin{array}{l}\mathrm{V} \\
1,3\end{array}$ & $\underset{1,3}{\mathbf{E}}$ \\
\hline \multirow{48}{*}{$\begin{array}{l}\text { SRP } \\
\text { (UoM } \\
2017 c \text { ) }\end{array}$} & Carbon & Carbon literacy accreditation & & & $\checkmark$ & & & \\
\hline & & Carbon management plan & & & $\checkmark$ & & & \\
\hline & Energy efficiency & Energy saving guides and audits & & & $\checkmark$ & & & \\
\hline & & Energy saving campaigns & & & $\checkmark$ & & & \\
\hline & & Energy-efficient infrastructure & & & $\checkmark$ & & & $(\checkmark)$ \\
\hline & & Revolving green and halls green funds & & & $\checkmark$ & & & $(\checkmark)$ \\
\hline & Water & Water saving guide & & & $\checkmark$ & & & \\
\hline & consumption & Efficient water systems & & & $\checkmark$ & & & $(\checkmark)$ \\
\hline & Sustainable travel & Enhanced transport infrastructure and partnership network & & & $\checkmark$ & & & $(\sqrt{ })$ \\
\hline & & Personalised travel plans & & & $\checkmark$ & & & \\
\hline & & Free inter-campus bus travel & & $(\checkmark)$ & $\checkmark$ & & & \\
\hline & & Virtual meeting & & & $(\checkmark)$ & & $\checkmark$ & \\
\hline & & Car sharing and electric car pooling & & $\checkmark$ & $(\checkmark)$ & & & $(\checkmark)$ \\
\hline & & Sustainable mileage and parking rates and discounts & & & $\checkmark$ & & & \\
\hline & & Smart driving training for staff & & & $\checkmark$ & & & \\
\hline & & Bike user group and cycling events & & & $\checkmark$ & & & \\
\hline & & Bike renting, second-hand purchasing and cycling facilities & & $\checkmark$ & $(\checkmark)$ & & & \\
\hline & & Run-commute group, events and facilities & & & $\checkmark$ & & & \\
\hline & & Walking programme (lunchtime strollers) and events & & & $\checkmark$ & & & \\
\hline & Sustainable & Energy and water saving guides & & & $\checkmark$ & & & \\
\hline & technical spaces & Green, lean and sustainable labs working groups & & & $\checkmark$ & & & \\
\hline & Sustainable & Code of practice for design teams & & & $\checkmark$ & & & \\
\hline & construction & BREEAM $^{\mathrm{b}}$ standard & & & $\checkmark$ & $(\checkmark)$ & & \\
\hline & & Environmental sustainability advisors & & & $\checkmark$ & & & \\
\hline & & Environmental sustainability project trackers & & & $\checkmark$ & $(\sqrt{ })$ & & \\
\hline & Waste reduction & Waste reduction and management guides & & & $\checkmark$ & & & \\
\hline & & Marketplace online platform & & $\checkmark$ & $(\checkmark)$ & & $(\checkmark)$ & \\
\hline & & Furniture for reuse store & & $\checkmark$ & $(\checkmark)$ & $(\sqrt{ })$ & & \\
\hline & & IT reuse centre & & $\checkmark$ & $(\checkmark)$ & $(\sqrt{ })$ & & \\
\hline & & Recycling facilities and contractors & & & $(\checkmark)$ & $\checkmark$ & & \\
\hline & & Mechanical biological treatment and anaerobic digestion & & & $(\checkmark)$ & $\checkmark$ & & \\
\hline & Responsible & Flexible framework & & & $\checkmark$ & & & $(\sqrt{ })$ \\
\hline & purchasing & NETpositive approach & & & $\checkmark$ & & & $(\sqrt{ })$ \\
\hline & & NETpositive supplier engagement tool & & & $\checkmark$ & & & $(\sqrt{ })$ \\
\hline & & Staff training programmes & & & $\checkmark$ & & & \\
\hline & & Top tips and product labels guides & & & $\checkmark$ & & & $(\sqrt{ })$ \\
\hline & & Whole-life costing guide & & & $\checkmark$ & & & $(\checkmark)$ \\
\hline & & Shared equipment inventory system & & $\checkmark$ & $(\sqrt{ })$ & & & \\
\hline & Sustainable IT & Service virtualisation & & & $(\checkmark)$ & & $\checkmark$ & \\
\hline & services & Computational shared facility & & $\checkmark$ & $(\sqrt{ })$ & & & \\
\hline & & IT services sustainability group & & & $\checkmark$ & & & \\
\hline & Sustainable & Fairtrade statement and animal welfare policy & $\checkmark$ & & & & & \\
\hline & catering and & Marine conservation society approved list & $\checkmark$ & & & & & \\
\hline & conferencing & Sustainable food policy and guides & & & $\checkmark$ & & & \\
\hline & & Reusable mugs and packaging & & $\checkmark$ & $(\checkmark)$ & & & \\
\hline & & Trayless dining areas with waste segregation & & & $\checkmark$ & & $(\sqrt{ })$ & \\
\hline & & Manchester veg people cooperative & $\checkmark$ & & & & & \\
\hline & & Sustainable restaurant association accreditation & & & $\checkmark$ & & & \\
\hline \multirow{10}{*}{$\begin{array}{l}\text { LCP } \\
\text { (UoM } \\
2017 d \text { ) }\end{array}$} & Key spaces and & Green infrastructure deployment & $\sqrt{ }$ & & & & & \\
\hline & species & Green roof and green wall policy & $\checkmark$ & & & & & \\
\hline & & Tree policy and trail & $\checkmark$ & & & & & \\
\hline & Key activities & Encouragement of active travel & & & $\checkmark$ & & & \\
\hline & & Stakeholder engagement with the environment & & & $\checkmark$ & & & \\
\hline & & Natural environment living lab projects & $\checkmark$ & & & & & \\
\hline & & Campus as fieldwork & $\checkmark$ & & $(\checkmark)$ & & & \\
\hline & & Initiatives to support healthy local communities & $(\checkmark)$ & & $\checkmark$ & & & \\
\hline & & Design and construction guidelines & $(\checkmark)$ & & $\checkmark$ & & & \\
\hline & & Animal positions and information tracker & & & $\checkmark$ & & & $(\checkmark)$ \\
\hline
\end{tabular}

${ }^{a}$ Re: Regenerate; S: Share; O: Optimise; L: Loop; V: Virtualise; E: Exchange. 1 = Preserve and enhance natural capital by controlling finite stocks and balancing renewable resource flows; 2 = Optimise resource yields by circulating materials in technical and biological cycles; 3 = Foster system effectiveness by revealing and designing out negative externalities. $\checkmark=$ primary purpose; $(\mathcal{V})=$ secondary effect.

${ }^{\mathrm{b}}$ BREEAM: Building Research Establishment Environmental Assessment Method. 


\subsection{Step B: Foreground analysis}

As part of the engagement of internal sustainability-related stakeholders, 12 university staff were interviewed, spanning technical and academic roles (see Table 3). They were selected as they are involved in the Environmental Sustainability Team which develops and evaluates sustainability management strategies. Thus, these stakeholders had the appropriate expertise and responsibilities to share meaningful inside knowledge and consider development of a future CE strategy.

Table 3 Organisational roles of the interviewed sustainability-related stakeholders

\begin{tabular}{ll}
\hline Technical & Academic \\
\hline Capital Projects Officer & Lecturer in Sustainable Chemical Engineering \\
Design Services Officer & Professor of Energy Efficiency \\
Environmental Officer of Residential Services & Professor of Environmental Governance \\
Environmental Sustainability Coordinator & Senior Lecturer in Climate Change \\
Environmental Sustainability Officer & \\
Procurement Officer & \\
Technical Services Officer & \\
Waste Management Officer & \\
\hline
\end{tabular}

\subsubsection{Stakeholders' understanding of circular economy and its link to sustainability}

The interviewees' understanding of the CE concept and its fundamental principles was mixed. Although only one participant was not aware of the CE concept at all, several participants showed limited understanding. As expected, academics and the environmental sustainability officers were more aware of the concept and its potential benefits. However, there was no common agreement around it. According to the Environmental Sustainability Coordinator, understanding the meaning and practical application of the CE concept is not straightforward:

"Many people do not know what it [circular economy] is. The [EMF] butterfly diagram is brilliant but what does it mean [in practice]? First of all, it is important to understand the [CE] principles and secondly, what can be done... We are trying to capture the circular economy concept in the sustainable resources plan but it is not entirely there yet because I do not know what it looks like for the university and how the university can implement it properly."

Many of the participants understood CE as the 3R (reduce, reuse and recycling) concept for waste management (EU 2008; EU 2010). However, the CE also encourages the design of restorative and regenerative systems for bio-based materials to re-enter the biosphere safely (resource cascading) and synthetic products to circulate at their highest quality for the longest possible time in closedloop systems (upcycling) (McDonough and Braungart 2003). Consequently, the CE goes beyond the 3R concept and the traditional notions of sustainability because solutions do not rest simply on improving the eco-efficiency of linear production and consumption systems, but rethinking the way product-service systems, businesses and supply chains are conceived (Figge and Hahn 2004).

Even though there have been attempts to clarify the CE concept (CIRAIG 2015, Blomsma and Brennan 2017) and provide a unified definition of it (Geissdoerfer et al. 2017; Murray et al. 2017), the lack of understanding of CE makes it difficult to envision how it can be implemented in practice and what benefits it may bring for organisations in different economic sectors. Likewise, Prendeville et al. (2017) suggest that the CE concept is dominated by a business-focused narrative for competitive advantage. This may limit its acceptance by non-profit organisations. Therefore, proper understanding of the CE concept represents a key challenge to overcome in order to obtain a buy-in from senior managers and operational staff. Accordingly, organisations may need to develop their own definition of CE to facilitate its adoption and support sustainability management processes (University of Edinburgh 2015). However, oversimplified goals based on weak foundations may reduce significantly the usefulness and applicability of the CE (Murray et al. 2017). Accordingly, Masi et al. (2017) argue that organisations should move away from using prescriptive CE definitions and practices towards a set of overarching principles able to guide, align and facilitate the implementation of future strategies. The importance of relying on CE guiding 
principles rather than definitions has been highlighted by the Lecturer in Climate Change as follows:

"We asked everyone [in our division] what does sustainability mean and every single answer was different... It depends on what you do, where you work, etc... there is no need for a common definition really. The important thing is to define some guiding principles... for instance, I do not understand sometimes what is the difference between circular economy and material efficiency by definition, so it is better to have guiding principles; something to work towards in the same way you have the waste hierarchy."

According to Broman and Robert (2017), a detailed definition of sustainability would be difficult for many people to agree upon and unwise to lock their minds into, considering the myriad of possibilities that exist for sustainable futures. Likewise, if the definition is very philosophical there is a risk of becoming diffuse or vague, which would constrain the analysis and validation of sustainable practices. It needs to be independent of scale and context. Thus, guiding principles offer a more generic, intuitive and practical approach to supporting sustainable development (Broman and Robert 2017). Arguably, this is also valid and applies to the CE concept.

These interview findings validate the results from the background analysis (Section 3.1) regarding the lack of explicit application of CE thinking in the development of the environmental sustainability strategy and action plans. The UoM has not embedded CE thinking in sustainability-based decision-making processes yet due to a lack of a clear understanding of the applicability of the concept and the potential benefits for the organisation. Consequently, it is important for the university to agree on a clear and principles-framed vision of $\mathrm{CE}$ that resonates with the organisation's core goals and priorities (UoM 2015) in order to encourage CE practice for sustainability management.

\subsubsection{Key requirements for embedding circular economy thinking into sustainability management}

\subsubsection{Decision-support frameworks, toolboxes and policy requirements}

Stakeholders advised that they do not use any particular framework and/or toolbox to support sustainability-based decision making at the senior and operational levels. The only exception is the procurement office which uses a structured decision-support framework - NETpositive approach (UoM 2017h) - to embed sustainability criteria in procurement processes. However, this framework is mostly qualitative, evaluating the sustainability performance of suppliers by relying on a number of pre-defined statements (NETpositive Futures 2017). By considering only these, suppliers can prioritise sustainable activities that may be more relevant or better resonate with their business. As a result, the created sustainability action plans may lead to modest incremental sustainability improvements (e.g. enhanced efficiencies) rather than more innovative solutions (e.g. materials closed-loop recycling).

Decisions taken by the university's Environmental Sustainability Team derive mostly from group meetings and workshops where stakeholders share information, propose solutions and agree on actions based on their knowledge and experience in the development of daily operations. This decision-making mechanism is practical and dynamic and it helps to raise sustainability awareness among staff. However, sustainability management calls for comprehensiveness in the assessment of opportunities (Sala et al. 2015). Using sustainability frameworks which incorporate CE guiding principles would ensure such comprehensiveness and robustness of decision-making processes, helping to align better long-term sustainability strategies with the core goals of the organisation (Mendoza et al. 2017).

For instance, solutions to enhance university's environmental sustainability should align with the three core goals defined in the Manchester 2020 Strategic Plan (UoM 2015) (Section 3.1.1). However, the priorities included in the Environmental Sustainability Strategy (UoM 2016) are limited in scope because they are mostly focused on reducing Scope 1 and Scope 2 carbon emissions (WBCSD 2001). Carbon reduction has been a driver across the HE sector since 2007 after the launch of the carbon management programme for universities (HEFCE 2010). Thus, the 
carbon reduction target is one of the key environmental sustainability KPIs for the university. However, this particular KPI does not necessarily promote implementation of a CE. Likewise, excluding Scope 3 emissions makes the carbon reduction targets less ambitious and misses out on improvement opportunities related to the organisation's indirect emissions (e.g. staff transport). Therefore, the application of life cycle thinking (UNEP/SETAC 2012) is essential for supporting strategic decision-making related to organisation's circularity and sustainability performance. Broadening the environmental KPIs beyond the carbon emissions to include other impacts normally considered in life cycle assessment, such as resource and ozone layer depletion, photochemical smog, acidification and ecotoxicity, is also important for promoting implementation of a CE as it can help identify innovative solutions and enhance significantly circularity in organisations (Mendoza et al. 2017).

Thus, it is important to ensure that CE principles and sustainability criteria are embedded properly in the corporate sustainability policies, goals, priorities and decision-support frameworks to avoid putting too much effort on the development of strategies that would only lead to incremental improvements (e.g. enhanced efficiencies) and may not have the capacity to challenge the unsustainable activities (Wells 2013). In the words of the Professor of Energy Efficiency:

"The strategic and operational priorities set by the university leadership team are transferred topdown to faculties and schools to develop their plans accordingly. If there is a weakness in the university-level strategic and operational priorities, that weakness is transferred top-down."

Accordingly, if a CE- and sustainability-related weakness is transferred top-down, changes made at the operational level will transfer reciprocally such weakness from the bottom-up. Thus, it is important to ensure that strategic CE guiding principles and sustainability criteria are embedded properly within research, teaching, outreach activities and campus management. According to the Technical Services Officer:

"Sustainability [including circular economy] does not have to be a separate subject and business goal. They can be so well embedded within research and teaching activities that they could be symbiotic."

Consequently, some stakeholders suggested that it was important to make everybody (e.g. staff, students and suppliers) a sustainability champion to pursue and facilitate the implementation of a CE in the workplace. An example of this can be found in the occupational health and safety (OHS) management systems (Robson et al. 2007; BSI 2007; HSE 2013; ISO 2018). Several stakeholders highlighted that $\mathrm{CE}$ and sustainability should both be implemented in the way OHS have been successfully embedded in daily business practice. Thus, it is important to understand how OHS, CE and sustainability management relate to each other in order to identify opportunities for integrating all these concepts in a single and standardised organisational management framework (OSHA 2016). According to the Technical Services Officer:

"By making people realise that they are responsible for the circular and sustainability management of their daily operations in the way they are responsible for their occupational health and safety it would encourage ownership and facilitate implementation... and circular economy and sustainability would not be considered another business priority but a common practice regardless of whether staff are research or teaching-oriented."

The use of such standardised framework by HEls would also help organisations to learn from each other, improve benchmarking and drive the development of strategies with implications for the whole HE sector, as suggested by the Lecturer in Sustainable Chemical Engineering. However, sustainability management frameworks and analytical tools are usually complex, difficult to apply and lack standardisation. The last is particularly challenging because each organisation is different and needs customised toolboxes (OECD 2009; UNEP 2014). Likewise, a buy-in from senior managers is essential for development of practical and successful decision-support frameworks. According to the Professor of Environmental Governance: 
"It is about making sure you get that relevant person in the room when you are talking about the approach you will use and how you will use it. You may end up doing something [e.g. a research project] that is very diluted but if it actually contributes to generate a change, then it is something more relevant than developing an impressive tool that will end up on the shelf and no one will use."

Thus, it is important to identify relevant senior leaders and managers to influence and obtain a full buy-in for development of suitable decision-support frameworks and toolboxes. Engaging relevant stakeholders in the design of such tools (e.g. by providing feedback) would encourage ownership and facilitate applicability (Azapagic 2003).

\subsubsection{Key performance indicators}

Stakeholders highlighted that the KPIs used to measure and monitor progress on environmental sustainability are not very informative and meaningful. According to the Professor of Energy Efficiency, whereas setting KPIs and reporting progress related to teaching and research is quite easy and common practice, setting KPIs for CE and sustainability management is quite challenging. Different KPIs can be used to monitor energy efficiency improvements, such as total energy consumption (per year, per $\mathrm{m}^{2}$, or per monetary unit) or GHG per unit of energy consumed. However, all these KPls will have advantages and disadvantages. For example, if energy consumption per $\mathrm{m}^{2}$ is used as a KPI to measure progress on energy efficiency and the built area is expanded without implementing new energy-efficient lighting or equipment, this KPI may indicate that the university is reducing its energy consumption, although that may not necessarily be the case. Likewise, if GHG emissions per unit energy consumed are used as a KPI and the national electricity mix is decarbonised, this KPI would show that the university is reducing its carbon footprint, without necessarily reducing its electricity demand. As a result, the use of inappropriate KPIs can lead to situations where ineffective incremental improvements are seen as progress towards a CE and sustainability. Such indicators are misleading and cannot drive innovative thinking needed to build circular and sustainable organisations (Kurucz et al. 2017). According to the Professor of Environmental Governance:

"Indicators are very good to increase baseline performance but they are not very good for encouraging innovation. For instance, setting a particular KPI to get an environmental certification would prevent some organisations to develop some of the most innovative stuff because sustainability indicators are limiting... Indicators do not necessarily reflect the sustainability of innovations."

Interestingly, F2B2 (2016) identified a number of shortcomings of sustainability reporting metrics in supporting business sustainability and innovation. According to the authors, traditional benchmarks to assess progress on corporate sustainability include progress relative to a baseline year, relative to current best practice and/or relative to business's own targets. Although these benchmarks serve to monitor progress, they only serve to demonstrate that businesses are becoming "less bad" than a baseline. As a result, they are not able to support long-term CE and sustainable value creation because if a company accepts less bad as good enough, then less bad is what it will achieve (Mendoza et al. 2017). Similarly, Pauliuk (2018) highlights that existing environmental and resource efficiency indicators do not necessarily reflect the CE principles properly due to the lack of systems perspective.

The necessary signals to motivate real change can only be generated with reference to a desired future state or ultimate goal beyond which organisations are able to create net positive sustainable value (F2B2 2016; Kurucz et al. 2017). Nevertheless, there are a number of challenges that should be overcome first to be able to define and use meaningful indicators. As suggested by the Professor of Environmental Governance:

"Tools application and KPI measurement is difficult when data does not exist or it is complex to collect."

One of the most relevant barriers to setting and calculating KPIs is related to data gathering. According to the Environmental Sustainability Officer, the environmental sustainability team spends 
a significant amount of time setting targets by analysing historical data records, market forecasts and getting expert advice (e.g. suppliers and operational staff). The team also checks what other universities and the Manchester City Council are doing in particular areas, such as waste management. However, there is no standardised method for use by universities to set and measure sustainability-related KPIs. Thus, the environmental sustainability team sometimes sets KPIs and targets similar to those set by other organisations, which may not be realistic or appropriate for the university. The main constraint is the lack of appropriate data collection procedures and systems. According to the Procurement Officer and the Environmental Sustainability Coordinator, current financial systems are not designed adequately to provide the information and data required to set robust KPIs and support the development of comprehensive CE and sustainability studies:

"Data recorded by financial systems is quite generic and aggregated...it does not capture any real granular level detail."

Additionally, the value proposition of the university (knowledge generation through teaching, research and outreach activities) is not directly linked to the procurement (purchase of 'stuff'). Consequently, it is difficult to relate purchases to the outputs in order to track resource flows and measure circularity and sustainability performance. The environmental sustainability team finds it also difficult to collect some data from suppliers because of the way contracts are set. For instance, the university does not pay waste collection and management by weight but by container lift (to be emptied), regardless of whether the containers are full or empty. Also, there are common spaces across the campus to store wastes, which makes it difficult to allocate waste streams per faculties and schools for more detailed evaluation. As a result, the organisation relies on generic estimations to calculate waste generation (e.g. average weight of a bin multiplied by the number of lifts per week).

Another limitation is the lack of centralised waste management systems for some waste streams (e.g. chemical and construction wastes). Whereas each university's school can make their own arrangements for the management and disposal of chemical wastes, the responsibility to manage construction wastes rests with construction contractors, who have their own waste managers. This makes it difficult to track the amount generated and the paths followed by these waste streams because construction waste managers do not report directly to the university. This highlights the importance of collaborating with suppliers and other stakeholders to design appropriate data collection and monitoring systems, which would in turn facilitate development of meaningful KPIs and targets.

\subsubsection{Barriers and opportunities for developing a circular economy strategy}

The stakeholders highlighted several barriers but also identified a range of opportunities for developing a CE strategy for the university - these are discussed in the following sections.

\subsubsection{Raising awareness about circular economy}

Several stakeholders stressed that raising awareness about CE and sustainability benefits is crucial for daily operation of the university. For instance, when researches need to buy new equipment, they prioritise the purchase of a high quality unit that will support the successful development of their research activities, even if it may lead to higher resource consumption and environmental impacts. The Manchester 2020 Strategic Plan (UoM 2015) encourages researchers to carry out world-class research but also to contribute to environmental sustainability and social responsibility. Therefore, it is important to raise awareness and demonstrate how CE and sustainability principles can be integrated and applied in daily practice. According to the Procurement Officer:

"Sometimes one needs to make a decision even if it is not the most [circular and] sustainable choice and it is alright if at least people are aware that they are not taking the most [circular and] sustainable decision." 
Consequently, the Procurement Officer suggested that it would be of great help to get access to a decision-support system that could facilitate the identification of best alternatives by combining product and service-related information on quality (value for money) with circularity and sustainability credentials (resource efficiency and environmental performance).

Awareness-raising must also involve students and suppliers. According to the Environmental Officer of Residential Services, the university spends an average of $£ 10 \mathrm{k}$ per month on studentrelated waste management. Therefore, the team actively encourages waste reduction and recycling among students. However, this is not a simple task as they need to influence student behaviour, set up a robust waste management logistics and ensure its effective use to avoid contamination of waste streams. Accordingly, the Waste Management Officer stressed that:

"It is extremely difficult and resource intensive to educate people to prevent and minimise waste, due to all the different cultures and the large number of people working and studying here... You can spend too much money in a big campaign to educate people to reduce waste generation but after a while everything goes back to normal. The biggest challenge is behavioural change towards [circular economy and] sustainability".

Consequently, the university should expand the sustainability engagement mechanisms already in place ('10,000 Actions' programme, Green Impact Teams and Sustainability Champions) to raise awareness of CE and motivate behavioural change for sustainable resource management.

\subsubsection{Applying value engineering effectively}

According to the Capital Projects Officer:

"In the real world of actually buying value for money and making sure construction projects [Campus Masterplan 2012] are delivered on time and stick to the budget, it is not always possible to implement circular economy and sustainability principles. Otherwise, the organisation would not be able to achieve other goals more related to the core priorities [teaching and research]."

The Officer explained that, when construction projects start to be affected by budget pressures, value engineering is applied to reduce costs. Value engineering is a systematic approach to finding alternatives to guarantee functional performance at a minimum cost (El-Alfy 2010; Mahadik 2015). It implies the substitution of products, processes, services or systems by less expensive solutions without compromising functionality. Consequently, value engineering usually leads to the removal of sustainability-related aspects from construction projects, resulting in buildings and constructed assets with lower circularity and environmental performance. According to the stakeholders, this is a difficult problem to manage because time, budget and resources are limited to be able to develop detailed studies to support CE- and sustainability-informed choices. Hence, knowing how to apply value engineering while enhancing circularity and sustainability performance of buildings and constructed assets is crucial. Likewise, the Design Services Officer suggested that it would be beneficial for designers to get access to practical guidance, toolboxes and a catalogue of materials and construction practices to facilitate an increase in the circularity and sustainability performance of constructed assets.

\subsubsection{Allocation of responsibilities and budgets}

Individual schools at the university do not have any budget allocated for development of CE and sustainability projects because this is under the remit of the Directorate of Estates and Facilities. Consequently, the schools do not benefit from the economic savings related to improvements in resource efficiency as these are handled centrally by the Directorate. This may discourage school managers to pursue the implementation of CE practices. Likewise, changing peoples' behaviour may also be more difficult as they cannot see a direct benefit to their school. Thus, the allocation of responsibilities between different university units should be revised to facilitate the implementation of CE thinking in daily practice across the university. A number of budget incentives and metrics for application in the schools should be developed to motivate them to pursue a CE and benefit from it. 
3.2.3.4. Mixed teams of senior managers and operational staff

Several stakeholders highlighted the importance of creating mixed teams combining operational and strategic staff to facilitate development of a realistic CE strategy and its effective implementation. Otherwise, top-down strategies formulated by senior managers may not be practical at the operational level because they are missing technical aspects. Likewise, staff focused only on operational management may lose track of the organisation's core goals and strategic priorities. It is therefore important to improve collaboration between the strategic leadership and the operational teams to avoid miscommunications that may affect the implementation of successful solutions. For instance, the Environmental Officer of Residential Services highlighted that:

"The initiative 'for every plant we cut we will plant two trees' [Living Campus Plan 2017] is good on paper but it is difficult in practice because no one wants to plant new trees as it causes too many problems [e.g. urban planning]".

Thus, a strategy built from the 'grass roots' can be better thought through and planned for bottomup implementation than the other way around. However, if CE and environmental sustainability are not championed and driven top-down by the senior management team, they may never be implemented in daily practice. The Lecturer in Sustainable Chemical Engineering suggested that the best way to develop a sustainable CE strategy is to follow the steps in environmental management systems (ISO 2015; EPA 2017).

Environmental management systems (EMS) require organisations to build a vision, set strategic goals, develop and implement an action plan and monitor and review progress (Azapagic 2003). These are well-known, simple and practical high-level management steps easy to follow by organisations. Therefore, embedding a CE strategy within the university's EMS would facilitate its easier and more effective implementation. This can be enhanced by appointing CE "champions" to challenge people at both the strategic and operational levels to think critically about CE and take appropriate actions across the university.

\subsubsection{Stakeholder engagement and collaboration}

According to the Environmental Sustainability Officer, there are many activities that the university can improve internally to develop and implement an effective CE strategy. However, there is a lot more change that needs to happen outside the university in order to build a CE strategy. For example, renting products is not widely available yet and existing renting companies cannot fulfil the needs of an organisation of the size of the University of Manchester. Regarding waste management, suppliers can take back some waste streams (e.g. packaging); however, they collect waste when there is a certain amount available. This means that there is a need to store waste for a period of time (e.g. six weeks) which is complex due to logistical constraints. Likewise, waste contractors do not usually want to collect waste from the labs for recycling because they consider waste to be contaminated, despite being reassured that it is completely safe and clean (e.g. broken equipment and worn-out materials).

Thus, the university does not have the required capability to develop certain CE- and sustainabilityrelated activities by itself. Indeed, it is unlikely that organisations alone could capture the full CE potential (Pauliuk 2018). Therefore, stakeholder partnership and collaboration are essential for cocreating solutions for CE implementation in the university and its value network, which includes suppliers, contractors, local communities and government bodies. Implementation of a CE strategy is discussed in the next section, as the last step of the framework proposed here.

\subsection{Further discussion}

The findings obtained in the background and foreground analyses suggest that the university has implemented to a certain extent most of the CE actions in the ReSOLVE checklist (Table 2) as part of the environmental sustainability actions and programmes. However, these have been developed without following the CE guiding principles due to a lack of understanding of the benefits and practical implementation of the CE concept within the university context. As a result, there are no initiatives and practices yet implemented which fully embed CE thinking and reflect the CE concept 
explicitly. Additionally, none of the implemented environmental sustainability initiatives has the capacity to motivate radical improvements in the sustainability performance if they are not accompanied by changes in the university's strategic and operational systems.

The application of the proposed framework to the case of the University of Manchester showed that the challenges for CE implementation include the lack of:

- awareness and understanding of the CE concept, principles, benefits and applicability to the university context;

- suitable analytical frameworks, data gathering systems and KPIs to identify, evaluate, prioritise, implement, monitor and manage CE solutions; and

- leadership teams, allocation of responsibilities, stakeholder engagement and effective policies targeting CE as an instrumental strategy for a long-term sustainability.

These challenges are not unique to the University of Manchester but are relevant to other HEls and the whole HE sector (as well as other sectors). For instance, the outcomes from the interviews resonate with the findings described by the University of Edinburgh (2015), which highlights an overall lack of awareness and understanding of CE among staff. It was also recognised that rigid institutional structures, ways of working and mindsets can constraint the implementation of a CE. Thus, a combination of top-down and bottom-up initiatives is required to drive the required change (University of Edinburgh 2015). Likewise, the use of campus and surrounding areas as living labs and experimental spaces for CE and sustainability practice would not only trigger a shift in the education paradigm (Kılkış 2017) but could influence stakeholders by showcasing the benefits of $\mathrm{CE}$ and sustainability innovations in ways that all those who engage will recognise, appreciate, learn from and emulate (Stephens et al. 2008).

Many of the identified CE barriers are also similar to those related to sustainability management in HEls (OECD 2010; Waas et al. 2012; Jorge et al. 2015). These include weak commitment and resistance to change, lack of strategic leadership and support from senior managers, conservative organisational structure and governance, limited specialisation, training and capability by staff, poor communication, lack of data collection systems and appropriate performance indicators, as well as few incentives and financial resources. Thus, applying learnings from the literature on sustainability management may facilitate the integration of CE thinking and practice by HEls because the CE concept overlaps with the notion of sustainable development (Whalen et al. 2018). Consequently, the findings from this study are not unique to the University of Manchester but can provide useful insights to motivate CE practice in other HEIs worldwide.

\section{Conclusions and recommendations}

This paper has proposed for the first time a methodological framework and guidance to help universities develop a circular economy strategy aimed at improving resource efficiency and environmental sustainability of their campus operations. The approach is compatible with broader sustainability management frameworks used by HEls as it follows the well-known iterative process of planning, doing, checking and improving. The application to the case of the University of Manchester has demonstrated that the framework is easy to use and can provide practical guidance in identifying challenges and opportunities for implementation of CE thinking.

Implementation of a CE in the higher education sector is in its infancy. Therefore, it has not been possible to demonstrate this part of the framework in practice - it is recommended that this be explored in future research. Further studies should also consider developing tools, effective data gathering systems and meaningful KPIs to help HEls measure circularity and monitor progress. Development of further case studies is also needed to share best practice and help other institutions build a business case for implementation of a CE. Finally, future work should also analyse the effectiveness of CE strategies with respect to environmental sustainability to avoid burden shifting and any rebound effects.

\section{Acknowledgements}

The authors would like to thank all the stakeholders that have participated in the development of the semi-structured interviews. Special thanks to Emma Gardner and Helen Cutts for their 
collaboration in the stakeholder engagement process. Adisa Azapagic is grateful to the Sustainable Consumption Institute at the University of Manchester for part-funding her time during the course of this study.

\section{References}

Accenture, 2015. Circular advantage: Innovative business models and technologies to create value in a world without limits to growth.

Accenture, 2017. Using digital technology to spin the circular economy. https://www.accenture.com/gb-en/insight-outlook-using-digital-tech-spin. Accessed: October 2017.

Amaral, L.P., Martins, N., Gouveia, J.B., 2015.Quest for a sustainable university: a review. Int J Sust Higher Education 16(2):155-172.

Antikainen, M., Valkokari, K., 2016. A framework for sustainable circular business model innovation. Technology Innovation Management Review 6(7): 5-12.

Arup, 2016. The Circular Economy in the Built Environment. London, UK.

Azapagic, A. 2003. Systems approach to corporate sustainability: a general management framework. Process Safety and Environmental Protection 81: 303-316.

Barbiroli, G., 2006. Eco-efficiency or/and eco-effectiveness? Shifting to innovative paradigms for resource productivity. Int J Sust Develop World Ecol 13(5): 391-395.

Blomsma, F., Brennan, G., 2017. The emergence of circular economy: a new framing around prolonging resource productivity. Journal of Industrial Ecology 21(3): 603-614.

Bocken, N.M.P., Short, S., Rana, P., Evans, S. 2014. A literature and practice review to develop sustainable business model archetypes. Journal of Cleaner Production 65: 42-56.

Bocken, N.M.P., 2015. Sustainable venture capital: catalyst for sustainable start-up success? Journal of Cleaner Production 108: 647-658.

Bocken, N.M.P., de Pauw, I., Bakker, C., van der Grinten, B. 2016. Product design and business model strategies for a circular economy. Journal of Industrial Product Engineering 33(5): 308320.

Bocken, N.M.P., Ritala, P., Huotari, P., 2017. The circular economy: exploring the introduction of the concept among S\&P 500 firms. Journal of Industrial Ecology 21(3): 487-490.

Boons, F., Lüdeke-Freund, F., 2013. Business models for sustainable innovation: state-of-the-art and steps towards a research agenda. Journal of Cleaner Production 45: 9-19.

BRE, 2017. BREEAM standard. Building Research Establishment (BRE) http://www.breeam.com/. Accessed: October 2017.

Braungart, M., McDonough, W., Bollinger, A., 2006. Cradle-to-cradle design: creating healthy emissions - a strategy for eco-effective product and system design. Journal of Cleaner Production 15 (13-14): 1337-1348.

Broman, G. I., Robert, K.H., 2017. A framework for strategic sustainable development. Journal of Cleaner Production 140(1): 17-31.

BSI, 2007. OHSAS 18001: Occupational health and safety management. London: BSI.

BSI 2017. BSI 8001 - Framework for implementing the principles of the circular economy in organizations: Guide. The British Standards Institution, London.

Carbon Trust, 2012. Further and higher education: training colleges and universities to be energy efficient. London, UK.

Camilleri, M.A., 2015. Valuing stakeholder engagement and sustainability reporting. Corporate Reputation Review 18(3): 210-222.

CIRAIG 2015. Circular economy: a critical literature review of concepts. Center for the Life Cycle of Products Processes and Services. Montreal, Quebec, Canada.

DEFRA, 2011. Sustainable procurement in government: guidance to the flexible framework. Department for Environment and Rural Affairs (DEFRA).

EAUC, 2016. Insight guide: education for a circular economy. Cheltenham, UK.

EEA, 2014. Annual European Union greenhouse gas inventory 1990-2012 and inventory report 2014. European Environment Agency (EEA): Luxembourg.

EEA, 2016. Circular economy in Europe: developing the knowledge base. European Environment agency (EEA). Luxembourg: Publications Office of the European Union.

El-Alfy, A.E.D., 2010. Design of sustainable buildings through value engineering. Journal of Building Appraisal 6(1): 69-79. 
Elia, V., Gnoni, M. G., Tornese, F., 2017. Measuring circular economy strategies through index methods: A critical analysis. Journal of Cleaner Production 142: 2741-2751.

EMF, 2015a. Growth Within: a circular economy vision for a competitive Europe. Isle of Wight: Ellen MacArthur Foundation (EMF)

EMF 2015b. Circular economy and curriculum development in higher education: Briefing notes, case studies and illustrative resources. Isle of Wight: Ellen MacArthur Foundation (EMF).

EMF 2015c. Higher education programmes. Isle of Wight: Ellen MacArthur Foundation (EMF).

EMF, 2015d. Higher education academic profiles. Isle of Wight: Ellen MacArthur Foundation (EMF).

EPA, 2017. Guide to developing an environmental management system. US Environmental Protection agency (EPA).

EU, 2008. Directive 2008/98/EC of the European Parliament and of the Council on waste and repealing certain Directives. Official Journal of the European Union L 312/3.

EU, 2010. Being wise with waste: the EU's approach to waste management. Accessed: October 2017.

EU, 2011. Connecting universities to regional growth: A practical guide. A guide to help improve the contribution of universities to regional development, with a view to strengthening economic, social and territorial cohesion, in a sustainable way. European Union (EU).

Eurostat 2018a. Annual net earnings. Single person without children. https://ec.europa.eu/eurostat/web/labour-market/earnings/database. Accessed: December 2018.

Eurostat 2018b. Annual municipal waste generation in the European Union. https://ec.europa.eu/eurostat/web/products-eurostat-news/-/DDN-20180123-1. Accessed: December 2018.

F2B2, 2016. Future-fit business benchmark (F2B2): concepts, principles and goals.

Ferrer-Balas, D., Lozano, R., Huisingh, D., Buckland, H., Ysern, P., Zilahy, G., 2010. Going beyond the rhetoric: system-wide changes in universities for sustainable societies. Journal of Cleaner Production 18: 607-610.

Figge, F., Hahn, T., 2004. Sustainable value added: measuring corporate contributions to sustainability beyond eco-efficiency. Ecological Economics 48: 173-187.

Gallego-Schmid, A., Schmidt, X.C., Stamford, L., 2018. Introduction of life cycle assessment and sustainability concepts in chemical engineering curricula. International Journal of Sustainability in Higher Education 19(3): 442-458.

Geisendorf, S., Pietrulla, F., 2017. The circular economy and circular economic concepts-a literature analysis and redefinition. Thunderbird Int Bus Rev 60: 771-782.

Geissdoerfer, M., Savaget, P., Bocken, N.M.P., Hultink, E.J., 2017. The Circular Economy: A New Sustainability Paradigm?. Journal of Cleaner Production 143: 757-768.

Ghisellini, P., Cialani, C., Ulgiati, S., 2016. A review on circular economy: the expected transition to a balanced interplay of environmental and economic systems. Journal of Cleaner Production 114: 11-32.

Hallstedt, S., Ny, H., Robert, K.H., Broman, G., 2010. An approach to assessing sustainability integration in strategic decision systems for product development. Journal of Cleaner Production 18: 70-712.

HEFCE, 2010. Carbon management strategies and plans: a guide to good practice. Higher Education Funding Council for England (HEFCE).

Heyes, G., Sharmina, M., Mendoza, J.M.F., Gallego-Schmid, A., Azapagic, A. 2018. Developing and implementing circular economy business models in service-oriented technology companies. Journal of Cleaner Production 177: 612-632.

HSE, 2013. A guide to health and safety regulation in Great Britain. Health and Safety Executive (HSE).

Ihobe, 2016. Encore regions and circular economy: best case studies 2016. Bilbao: Department of Environment and Territorial Policy, Basque Government.

ISO 2015. ISO 14001 - Environmental management systems: requirements with guidance for use. International Standardisation Organisation (ISO): Geneva.

ISO 2018. ISO 45001 - New international Standard for occupational health and safety management systems. International Standardisation Organisation (ISO): Geneva. 
IWA, 2016. Water utility pathways in a circular economy. The International Water Association (IWA): London.

Jorge, M.L., Madueno, J.H., Cejas, M.Y.C., Pena, F.J.A., 2015. An approach to the implementation of sustainability practices in Spanish universities. Journal of Cleaner Production 106: 34-44.

JRC, 2017. Level(s) - A common EU framework of core sustainability indicators for office and residential buildings. Parts 1 and 2: Introduction to Level(s) and how it works (Draft Beta v1.0). Joint Research Centre (JRC), Directorate B, Growth and Innovation, Unit 5, Circular Economy and Industrial Leadership, European Commission: Seville.

Kraaijenhagen, C., van Oppen, C., Bocken, N.M.P., 2016. Circular Business: Collaborate and Circulate. Circular Collaboration [Amersfoort].

Kılkış, S., 2017. Comparative analyses of sustainable campuses as living laboratories for managing environmental quality. Management of Environmental Quality: An International Journal 28(5): 681-702.

Kopnina, H., 2018. Circular economy and Cradle to Cradle in educational practice. Journal of Integrative Environmental Sciences 15(1): 123-138.

Kudryashova, A., Genkov, A., Mo, T., 2015. Certification schemes for sustainable buildings: assessment of BREEAM, LEED and LBC from a strategic sustainable development perspective. $\mathrm{PhD}$ thesis, Blekinge Institute of Technology, Karlskrona, Sweden.

Kurucz, E.C., Colbert, B.A., Lüdeke-Freund, F., Upward, A., Willard, B., 2017. Relational leadership for strategic sustainability: practices and capabilities to advance the design and assessment of sustainable business models. Journal of Cleaner Production 140: 189-204.

Lieder, M., Rashid, A., 2016. Towards circular economy implementation: a comprehensive review in the context of manufacturing industry. Journal of Cleaner Production 115: 36-51.

Mahadik, U.A., 2015. Value engineering for cost reduction and sustainability in construction projects. IOSR Journal of Mechanical and Civil Engineering (IOSR-JMCE): 95-97.

Masi, D., Day, S., Godsell, J., 2017. Supply chain configurations in the circular economy: a systematic literature review. Sustainability 9 (9), 1602.

McDonough, W., Braungart, M., 2003. Cradle to cradle: remaking the way we make things. New York: North Point.

McDowall, W., Geng, Y., Huang, B., Bartekov, E., Bleischwitz, R., Turkeli, S., Kemp, R., Domenech, T., 2017. Circular economy policies in China and Europe. Journal of Industrial Ecology 21(3): 651-661.

McKinsey, 2015. The internet of things: mapping the value beyond the hype.

Mendoza, J.M.F., Sharmina, M., Gallego-Schmid, A., Heyes, G., Azapagic, A., 2017. Integrating backcasting and eco-design for the circular economy: the BECE framework. Journal of Industrial Ecology 21 (3): 526-544.

Murray, A., Skene, K., Haynes, K., 2017. The circular economy: an interdisciplinary exploration of the concept and application in a global context. Journal of Business Ethics (140): 369-380

NETpositive Futures, 2017. The NETpositive supplier engagement tool. http://netpositivefutures.co.uk/netpositive-supplier-engagement/. Accessed: October 2017.

NUS, 2017. NUS green impact. https://sustainability.nus.org.uk/green-impact. Accessed: October 2017.

Lewandowski, M., 2016. Designing the business models for circular economy-towards the conceptual framework Sustainability 8: 43.

Lukman, R., Glavic, P., 2007. What are the key elements of a sustainable university? Clean Techn Environ Policy 9:103-114.

OECD, 2009. Sustainable manufacturing and eco-innovation: framework, practices and measurement. Organisation for Economic Cooperation and Development (OECD).

OECD, 2010. Higher education for sustainable development. Final Report of International Action Research Project. Organisation for Economic Cooperation and Development (OECD).

OSHA, 2016. Sustainability in the workplace: a new approach for advancing worker safety and health. U.S. Occupational Safety and Health Administration.

Pauliuk, 2018. Critical appraisal of the circular economy standard BS 8001:2017 and a dashboard of quantitative system indicators for its implementation in organizations. Resources, Conservation \& Recycling 129: 81-92.

Prendeville, S., Cherim, E., Bocken, N.M.P., 2017. Circular cities: mapping six cities in transition. Environmental Innovation and Societal Transitions 26: 171-194. 
Ramos, T., B., Caeiro, S., van Hoof, B., Lozano, R., Huisingh, D., Ceulemans, K., 2015. Experiences from the implementation of sustainable development in higher education institutions: environmental management for sustainable universities. Journal of Cleaner Production 106: 3-10.

Reed, M.S., Graves, A., Dandy, N., Posthumus, H.M Hubacek, K., Morris, J., Prell, C., Quinn, C.H., Stringer, L.C., 2009. Who's in and why? a typology of stakeholder analysis methods for natural resource management. Journal of Environmental Management 90: 1933-1949.

Robson, L.S., Clarke, J.A., Cullen, K., et al. 2007. The effectiveness of occupational health and safety management system interventions: a systematic review. Safety Science 4: 329-353.

Sala, S., Ciuffo, B, Nijkamp, P., 2015. A systemic framework for sustainability assessment. Ecological Economics 119: 314-325.

Sauvé, S., Bernard, S., Sloana, P., 2016. Environmental sciences, sustainable development and circular economy: Alternative concepts for trans-disciplinary research. Environ Develop17: 4856.

Stephens, J.C., Graham, A.C., Toward an empirical research agenda for sustainability in higher education: exploring the transition management framework. J Clean Prod 18: 611-618.

Swap and Re-use Hub, 2017. https://www.ed.ac.uk/local/projects/shrub-swap-and-re-use-co-op. Accessed: September 2017.

Three C, 2014. A didactical approach for education for a circular economy. Discussion paper: entrepreneurial learning-topics and a didactical approach for a circular economy. Three C: Fontys University of Applied Sciences. http://www.threec.eu/wp-content/uploads/2015/05/adidactical-approach-for-a-circular-economy.pdf. Accessed: September 2017.

Too, L., Bajracharya, B., 2015. Sustainable campus: engaging the community in sustainability. International Journal of Sustainability in Higher Education 16(1): $57-71$.

UK Green Building Council, 2017. Practical how-to guide: build circular economy thinking Into Your Projects.

UNEP, 2014. Eco-innovation manual. Environmental Nations Environment Programme (UNEP): Kenya.

UNEP/SETAC, 2012. Greening the economy through life cycle thinking: ten years of the UNEP/SETAC Life Cycle Initiative. Paris; United Nations Environment Program (UNEP) and Society of Environmental Toxicology and Chemistry (SETAC).

UoM, 2012. Campus Masterplan 2012-2022. The University of Manchester (UoM). http://documents.manchester.ac.uk/display.aspx?DoclD=15305. Accessed: September 2017.

UoM, 2015. Manchester 2020: The University of Manchester's strategic plan. The University of Manchester (UoM http://documents.manchester.ac.uk/display.aspx?DoclD=25548. Accessed: September 2017.

UoM, 2016. Environmental sustainability strategy: building on our heritage to create a sustainable future. The University of Manchester (UoM). http://documents.manchester.ac.uk/display.aspx?DoclD=33155\%20. Accessed: September 2017.

UoM, 2017a. Facts and figures. The University of Manchester (UoM). http://documents.manchester.ac.uk/display.aspx?DoclD=31312. Accessed September 2017.

UoM, 2017b. The university estates. The University of Manchester (UoM). http://www.estates.manchester.ac.uk/ourestate/. Accessed: September 2017.

Uo $\bar{M}, 2017 \mathrm{c}$. Sustainable resources plan: supporting the responsible use of natural resources and materials. The University of http://documents.manchester.ac.uk/display.aspx?DoclD=33195. Accessed: September 2017.

UoM, 2017d. Waste management. The University of Manchester (UoM). http://www.estates.manchester.ac.uk/services/es/waste/. Accessed: September 2017.

UoM, 2017e. Living campus plan: a living campus where we work alongside nature and nature works alongside us. The University of Manchester (UoM). http://documents.manchester.ac.uk/display.aspx?DoclD=33154\%20. Accessed: September 2017.

UoM, 2017f. 10,000 Actions. The University of Manchester (UoM). http://www.socialresponsibility.manchester.ac.uk/signature-programmes/10000-actions/.

Accessed: September 2017. 
UoM, 2017g. Sustainability champions. http://www.sustainability.manchester.ac.uk/getinvolved/staff/champions/. Accessed: September 2017.

UoM 2017h. Responsible procurement: a NETpositive approach utilising the flexible framework. The University of Manchester (UoM). http://www.procurement.manchester.ac.uk/procurementexcellence/netpositiveprocurement/then etpositivecoreapproach/. Accessed: September 2017.

University of Edinburgh, 2015. Circular economy thinking and action at the University of Edinburgh. https://www.ed.ac.uk/about/sustainability/news/archived-news/2015/circular-economy-reportpublished. Accessed: September 2017.

Velazquez, L., Munguia, N., Platt, A., Taddei, J., 2006. Sustainable university: what can be the matter?. Journal of Cleaner Production 14(9-11): 810-819.

Vivanco, D.F., Sala, S., McDowall, W., 2018. Roadmap to Rebound: How to Address Rebound Effects from Resource Efficiency Policy. Sustainability 2018, 10(6): 1-17.

Waas, t., Hugé, J., Ceulemans, K., Lambrechts, W-, Vandenabeele, J., Lozano, R., Wright, T., 2012. Sustainable higher education: understanding and moving forward. Flemish Government Environment, Nature and Energy Department, Brussels.

WARP-it re-use online portal, 2017. https://www.ed.ac.uk/estates/waste-recycling/reuseexchange/what-is-warpit. Accessed: September 2017.

WBCSD, 2001. The Greenhouse Gas Protocol: a corporate accounting and reporting standard. World Business Council for Sustainable Development (WBCSD): Switzerland.

Wells, P., 2013. Business models for sustainability. Cheltenham: Edward Elgar Publishing.

Whalen, K. A., Berlin, C., Ekberg, J., Barletta, I., Hammersberg, P., 2018. All they do is win': lessons learned from use of a serious game for circular economy education. Resources, Conservation \& Recycling 135: 335-345.

Winans, K., Kendall, A., Deng, H., 2018. The history and current applications of the circular economy concept. Renewable and Sustainable Energy Reviews, 68(1): 825-833.

Witjes, S., Lozano, R., 2016. Towards a more Circular Economy: Proposing a framework linking sustainable public procurement and sustainable business models. Resources, Conservation and Recycling 112: 37-44.

Young, W., Tilley, F., 2006. Can businesses move beyond efficiency? The shift toward effectiveness and equity in the corporate sustainability debate. Bus Strat Env 15(6): 402-415.

Zink, T., Geyer, R., 2017. Circular Economy Rebound. J Ind Ecol 21(3): 593-602. 


\title{
A methodological framework for the implementation of circular economy thinking in higher education institutions: Towards sustainable campus management
}

\author{
Joan Manuel F. Mendoza, Alejandro Gallego-Schmid and Adisa Azapagic
}

\section{SUPPORTING INFORMATION}

Table S1. Steps and criteria for CE implementation and sustainability management in organisations.

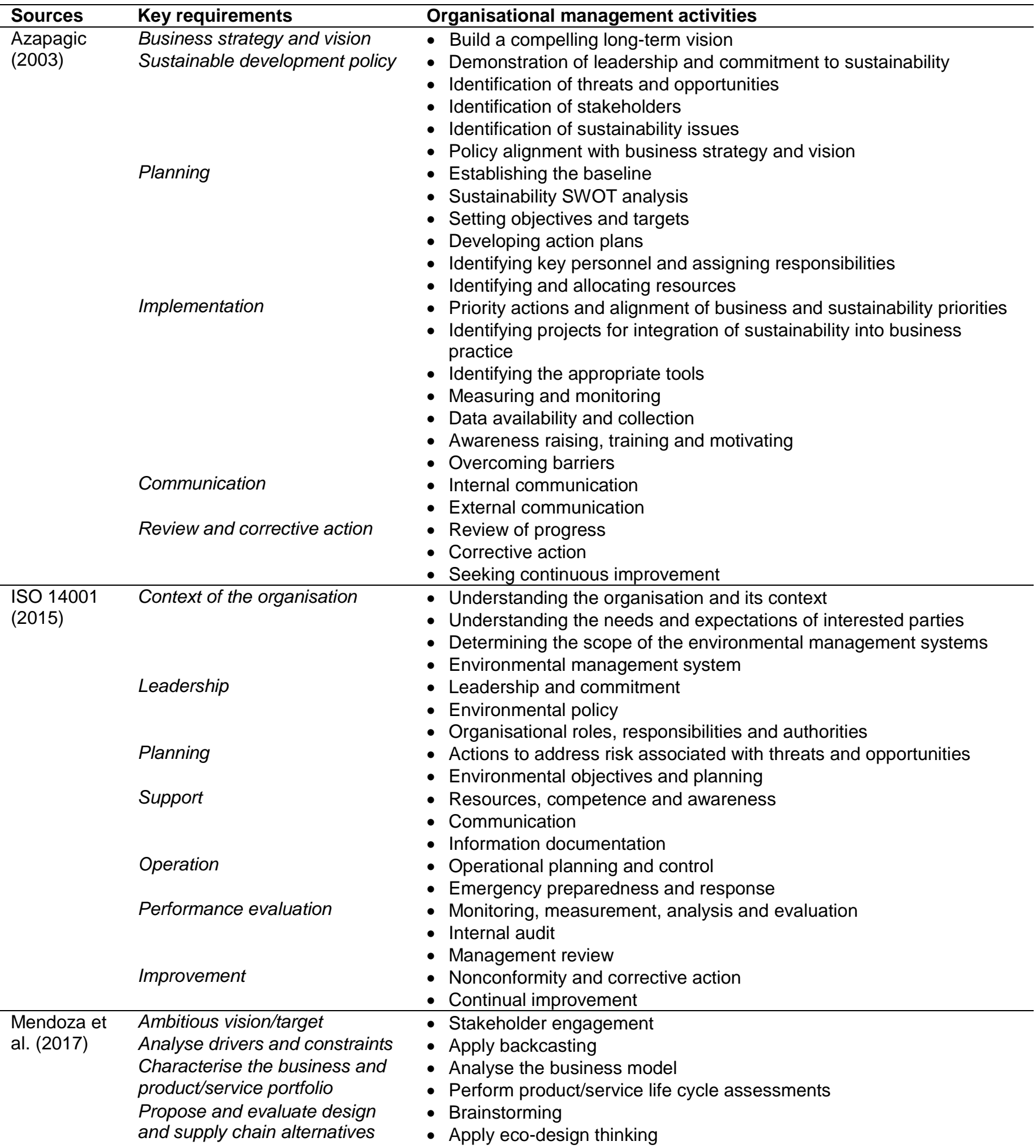




\begin{tabular}{|c|c|c|}
\hline Sources & Key requirements & Organisational management activities \\
\hline & $\begin{array}{l}\text { Devise and validate scenarios } \\
\text { and a scaled-up business plan } \\
\text { Implement and review }\end{array}$ & $\begin{array}{l}\text { - Assess the technical and socio-economic feasibility of alternatives } \\
\text { - Apply systems thinking } \\
\text { - Analyse the effects of business model innovations } \\
\text { - Develop an action plan and roadmaps } \\
\text { - Execute the action plan } \\
\text { - Set appropriate key performance indicators } \\
\text { - Monitor progress and take improvement actions }\end{array}$ \\
\hline $\begin{array}{l}\text { BS 8001 } \\
(2017)\end{array}$ & $\begin{array}{l}\text { Framing } \\
\text { Scoping } \\
\text { Idea generation } \\
\text { Feasibility } \\
\text { Business case } \\
\text { Piloting and prototyping } \\
\text { Delivery and implementation } \\
\text { Monitor, review and report }\end{array}$ & $\begin{array}{l}\text { - Assess current state of play and relevance of the circular economy } \\
\text { - Stakeholder mapping } \\
\text { - Generate internal awareness and enthusiasm } \\
\text { - Identify the systems to be explored and influenced } \\
\text { - Understand the organisation's current vision and how the circular } \\
\text { - Agree on vision and high-level strategy } \\
\text { - Define goals and clear briefs/topics for exploration } \\
\text { - Identify list of ideas/options and prioritise accordingly } \\
\text { - Define and undertake feasibility assessment } \\
\text { - Review and/or confirm ideas/options } \\
\text { - Develop detailed business case } \\
\text { - Establish ownership and governance } \\
\text { - Develop a plan for piloting, prototyping or development } \\
\text { - Conduct and review pilot/prototype } \\
\text { - Develop and execute delivery plan and its implementation } \\
\text { - Mechanisms to measure progress over time } \\
\text { - Monitoring and measurement } \\
\text { - Reporting progress } \\
\text { - Continual and transformational improvement }\end{array}$ \\
\hline
\end{tabular}

Table S2. CE strategy implementation checklist

\begin{tabular}{|c|c|}
\hline CE implementation & Organisational and operational requirements \\
\hline Build a corporate vision & $\begin{array}{l}\text { - } \quad \text { Define an overarching strategic vision congruent with CE principles } \\
\text { - } \quad \text { Analyse drivers and constraints } \\
\quad \text { Agree on the CE vision and a high-level strategy }\end{array}$ \\
\hline Create a leadership team & $\begin{array}{ll}\text { - } & \text { Identify and engage relevant stakeholders } \\
\text { - } & \text { Define organisational roles, skills and responsibilities } \\
\text { - } & \text { Ensure leadership commitment, internal awareness and enthusiasm to CE }\end{array}$ \\
\hline Perform a framing and scoping study & $\begin{array}{l}\text { - Assess the organisation's baseline performance against CE } \\
\text { - Identify the organisation's needs and stakeholder expectations } \\
\text { Determine the scope of a CE management system }\end{array}$ \\
\hline Develop an action plan & $\begin{array}{l}\text { - Set objectives and targets for exploration } \\
\text { - } \quad \text { Identify and allocate resources and competences } \\
\text { - Select appropriate tools to assess opportunities to drive change } \\
\text { - Devise and assess the feasibility of organisational and operational CE } \\
\text { solutions }\end{array}$ \\
\hline Build the business case and strategy & $\begin{array}{l}\text { - } \quad \text { Build a scaled-up CE strategy with a roadmap } \\
\text { - Set priority actions aligned with the corporate core goals } \\
\text { - Secure top-level ownership, buy-in and governance }\end{array}$ \\
\hline Communicate and execute the strategy & $\begin{array}{l}\text { - } \quad \text { Develop projects to put the CE strategy into practice } \\
\text { - } \quad \text { Raise awareness and train staff on CE management } \\
\text { - }\end{array}$ \\
\hline $\begin{array}{l}\text { Monitor and report progress against the } \\
\text { strategy }\end{array}$ & $\begin{array}{l}\text { - Set mechanisms and indicators to measure CE progress over time } \\
\text { - } \quad \text { Integrate CE metrics within sustainability reporting systems } \\
\text { - Facilitate continual and transformational improvement }\end{array}$ \\
\hline Revise and improve the strategy & $\begin{array}{l}\text { - Run internal audits and management review processes } \\
\text { - Take corrective action for continuous improvement }\end{array}$ \\
\hline
\end{tabular}


Table S3. Topic areas, baseline values and targets described by the Sustainable Resources Plan (SRP) and the Living Campus Plan (LCP) of the University of Manchester.

\begin{tabular}{|c|c|c|c|c|}
\hline Action plans & Delivery area & Topic area & $\begin{array}{l}\text { Baseline } \\
(2014 / 2015)\end{array}$ & 2022 target \\
\hline \multirow[t]{10}{*}{ SRP (UoM 2017a) } & Carbon & Scope 1 and 2 carbon emissions & $80.6 \mathrm{kt} \mathrm{CO} 2$ & $\downarrow 40 \%$ \\
\hline & Energy efficiency & Energy consumption & $246.6 \mathrm{GWh}$ & $\downarrow 5 \%$ \\
\hline & Water consumption & Water consumption & $742,370 \mathrm{~m}^{3}$ & - \\
\hline & Sustainable travel & $\begin{array}{l}\text { Fully electric fleet vehicles } \\
\text { Electric charging bays }\end{array}$ & $\begin{array}{l}4 \\
8\end{array}$ & $\begin{array}{l}20 \\
16\end{array}$ \\
\hline & $\begin{array}{l}\text { Sustainable technical } \\
\text { spaces }\end{array}$ & $\begin{array}{l}\text { People involved in sustainability } \\
\text { Green Impact Labs teams }\end{array}$ & $\begin{array}{l}160 \\
27\end{array}$ & $\begin{array}{l}250 \\
50\end{array}$ \\
\hline & Sustainable construction & $\begin{array}{l}\text { Capital projects of } £ 5 m+\text { with ESA } \\
90 \% \text { of projects to achieve }>95 \% \text { of } \\
\text { environmental sustainability targets }\end{array}$ & - & $\begin{array}{l}100 \% \\
90 \%\end{array}$ \\
\hline & Waste reduction & $\begin{array}{l}\text { Reuse through furniture reuse store } \\
\text { Reuse in student residences } \\
\text { Recycling - segregated at source }\end{array}$ & $\begin{array}{l}220 t \\
130 t \\
1,612 t\end{array}$ & $\begin{array}{l}\uparrow 5 \% \\
\uparrow 10 \% \\
\uparrow 20 \%\end{array}$ \\
\hline & Responsible purchasing & Flexible Framework & Level 4 & Level 5 \\
\hline & Sustainable IT services & $\begin{array}{l}\text { Baseline data to be collected and } \\
\text { targets to be developed } 2018\end{array}$ & - & - \\
\hline & $\begin{array}{l}\text { Sustainable catering and } \\
\text { conferencing }\end{array}$ & $\begin{array}{l}\text { Areas segregating food waste } \\
\text { Sustainable Restaurant Association }\end{array}$ & $\begin{array}{l}0 \\
-\end{array}$ & $\begin{array}{l}2 \\
3 \text { stars }\end{array}$ \\
\hline \multirow[t]{2}{*}{ LCP (UoM 2017b) } & Key spaces and species & $\begin{array}{l}\text { Brown roofs } \\
\text { Green walls } \\
\text { Trees }\end{array}$ & $\begin{array}{l}90 \mathrm{~m}^{2} \\
447 \mathrm{~m}^{2} \\
9,189\end{array}$ & $\begin{array}{l}+2 \text { projects } \\
+2 \text { projects } \\
2 \text { trees } 1 \\
\text { removed }\end{array}$ \\
\hline & Key activities & $\begin{array}{l}\text { Staff active travel } \\
\text { Student active travel } \\
\text { Living campus champions } \\
\text { Biodiversity projects } \\
\text { Staff wellbeing } \\
\text { Student wellbeing } \\
\text { Value of wellbeing }\end{array}$ & $\begin{array}{l}22 \% \\
37 \% \\
- \\
- \\
49 \\
55 \\
£ 67.8 \mathrm{~m} \\
\end{array}$ & $\begin{array}{l}25 \% \\
39 \% \\
26 \\
1 \text { project } \\
58 \\
60 \\
£ 79 \mathrm{~m} \\
\end{array}$ \\
\hline
\end{tabular}

S1. Semi-structured questionnaire

Corporate strategy assessment

Q.1 How was the University's Strategy Plan developed? How were the vision, including the guiding principles and values, the core goals, key strategies and key performance indicators set?

Q.2 Are you familiar with the circular economy concept? Is the concept of circular economy embedded in University's Strategy Plan? How well do you think the Strategy Plan integrates sustainability criteria linked to circular economy principles?

\section{Organisational management}

Q.3 What are the main principles, criteria and aspects guiding the operations of your School/Division? And how do they relate to circular economy and sustainability?

Q.4 How were the environmental sustainability vision, goals and actions included in the Environmental Sustainability Strategy developed? Does your School/Division have its own environmental sustainability plan?

Q.5 What approaches, methods, tools and indicators are used at senior management levels to identify, evaluate and prioritise decisions to address short-, medium- and longterm sustainability challenges, including pursuing a circular economy? 
Q.6 Who has developed such sustainability methods, tools and indicators (referred to in the above question)? How has this been done (criteria behind it)? Are they efficient and effective enough for reliable goal setting and achievement?

Q.7 How are decisions taken at the senior management level transferred top-down (communication channels) to different Faculties, Schools and Departments at the University and how do they influence (guide through implementation) downstream operational activities?

Q.8 What kind of criteria, methods, tools and indicators are usually used at the operational levels to identify, evaluate and prioritise sustainable and circular economy decisions? What is the flexibility (freedom) of each Faculty, School, Department and Units to undertake (implement) sustainable actions?

Q.9 How are the operational-level decisions taken in different areas of the University translated bottom-up and how do they influence senior management considerations and decision-making processes related to sustainability?

\section{Improvement opportunities}

Q.10 How can University's decision-making processes be improved at the senior and operational levels to manage comprehensively and more effectively long-term sustainability and circular economy challenges?

\section{S2. Comprehensive analysis of the contribution of the university's environmental} sustainability strategies to the ReSOLVE actions.

\section{S2.1 Regenerate}

Regenerate CE activities are aimed at safeguarding, reclaiming and increasing the resilience of ecosystems. It includes restoring the natural land, returning recovered biological resources safely to the biosphere in order to replenish the soil and shifting to renewable materials and energy in substitution of fossil resources (EMF 2015).

Many of the environmental sustainability activities associated with the LCP (Table 1 in the paper) fall into this category because they have the main purpose of providing highquality greenspace to support biodiversity (e.g. invertebrate, bird species and bat populations), natural resilience to climate change and social wellbeing (e.g. health). A green roof and green wall policy has been developed for this purpose. Likewise, the organisation supports the tree policy and trail by planting two trees for every one removed. The university also encourages the use of open space as living labs for research, teaching and learning about nature. For instance, the UMAPIT (University of Manchester Animal Positions and Information Tracker) app has been developed to allow users to record sightings of urban wildlife species and connect people with the environment.

Complementarily, several sustainable catering activities described by the SRP represent additional examples of solutions oriented to preserve and enhance the natural environment (Table 1 in the paper). For instance, Fairtrade tea, coffee, hot chocolate, sugar and juices are available through all the university outlets (Fairtrade statement). Also, $100 \%$ of the milk, $80 \%$ of the eggs and $50 \%$ of the beef is organic and free range and all the fish served is Marine Stewardship Council certified (animal welfare policy). Likewise, a start-up cooperative has been created (Manchester Veg People 2017) to increase the number of local, organic and seasonal vegetable growers and consumers in and around Manchester. The university spends around £40,000 a year through this cooperative. 
All these activities could therefore be reinforced and/or extended further by applying strategic CE thinking. Considering the vast area of land occupied by the University of Manchester, part of it could be dedicated to build local orchards and communal gardens across the campus, including the implementation of rooftop greenhouses (RTG) and vertical farms. The integration of RTG in buildings represents an ecoinnovative food production concept to facilitate an efficient management of energy, water, carbon dioxide and material resources in closed-loop systems (Sanye-Mengual et al. 2012). According to Sanye-Mengual et al. (2014), food production through RTG can benefit from the use of residual air (heat and $\mathrm{CO}_{2}$ ) and harvested rainwater from the building, whereas buildings can benefit from better indoor comfort with lower energy inputs (e.g. heating and ventilation requirements). The exchange of residual air from the building can provide cost- and environmental burden-free $\mathrm{CO}_{2}$ RTG-soil enrichment, increasing the crop efficiency. Likewise, the use of harvested rainwater can make RTG food production self-sufficient. The RTG insulation can also increase the thermal comfort of buildings, leading to more liveable and cost-effective spaces. As a result, the sustainability performance of both systems can be enhanced reciprocally and simultaneously (Sanye-Mengual et al. 2014). Consequently, RTG represent a CE alternative worth for exploration for implementation in the university campus because it could not only help designing more sustainable buildings to actively achieving the carbon reduction target and environmental sustainability goals described in the SRP but also to facilitate teaching, research and living lab activities to educate and engage student, staff, stakeholders and the general public in CE and sustainability practice.

\section{S2.2. Share}

Share CE activities seek maximising the use intensity and prolonging the utilisation period of materials, products and assets in order to slow down resource flows from production to final disposal (Stahel 1994; Accenture 2015). It entails peer-to-peer renting, leasing and pooling of under-used goods as well as repairing and reusing products through second-hand markets (EMF 2015). Complementary sharing activities include co-living, co-location and flexible working to make a greater use of offices and workplaces (ARUP 2016).

Several sharing platforms have been implemented across the University of Manchester with the purpose of reducing waste generation (Table 1 in the paper). For instance, the university encourages staff to share and reuse products and equipment through the marketplace, the furniture for reuse store and the IT reuse centre. The marketplace (UoM 2017c) is an online platform available for staff to advertise, sell and buy any kind of reusable products, such as electronics, musical instruments, home and garden, clothing and everything else. Likewise, the furniture that cannot be reused locally (e.g. within the same building) is collected and deposited in the furniture for reuse store (UoM 2017d) for redistribution across the campus. Thanks to this initiative around 103 tonnes of unwanted furniture were diverted from landfill in 2014/15. Furniture to the value of $£ 207 k$ was reused across the campus and another $£ 232 k$ worth of furniture was donated to local charities. Similarly, redundant IT equipment is sent to the IT reuse centre (UoM 2017e) where the equipment is checked for faults and data is wiped from hard discs in order to be reused. Over 20 tonnes of redundant IT equipment was reused between 2010 and 2013 across the campus, saving over 120 tonnes of GHG emissions compared to buying new equipment.

Focusing on sustainable travel, the university has a $100 \%$ Nissan Leaf pooling car that can be used by staff to undertake business journeys in substitution of internalcombustion engine vehicles. Additionally, a bike user group provides bike hire and second-hand purchase schemes and there are eight shelters, three repair stands and two rapid pumps across the campus to encourage and facilitate cycling. 
Likewise, the university has banned the use of disposable cups in all the residences to promote the utilisation of reusable cups ("Hug Mugs") (UoM 2017f) as a strategy to support sustainable catering. Reusable cups are sold in all the cafes and restaurants across campus for $£ 6$ and users can save 20p each time they buy hot drinks or soup. Food suppliers are also encouraged to use reusable packaging (e.g. containers and crates) to deliver products to canteens.

Finally, researchers can rent and share the use of equipment through the online database N8 Shared Equipment Inventory System (N8 2017) held by the UK Northern Universities. The IT service also offers the alternative to access to a computational shared facility that provides effective and efficient computing for staff that needs to keep their computers running $24 / 7$ due to research computations.

All these activities contribute actively to improve the university's resource efficiency by giving products a second, or multiple, life cycle(s). Consequently, reinforcing and expanding the internal reuse and sharing schemes represent a strategic priority to increase the circularity and sustainability performance of the organisation. For instance, the space utilisation rate of the whole university is equivalent to $20 \%$ (UoM 2010). Thus, the organisation could complement the above mentioned strategies with the implementation of space sharing activities in offices, labs, conference and workshop and residences to use available space more efficiently. Co-location, sharing underused facilities, repurposing existing floor space and providing flexible working solutions can generate notable resource, environmental and economic savings (EMF 2015). According to ARUP (2016), by occupying less space and minimising the time an asset is idle, fewer resources are needed to deliver the same function. The Campus Masterplan (UoM 2012) is trying to address this issue through re-location, co-location and new building and facility design (e.g. fitness for purpose). However, more efforts is required to overcome the barriers related to poor space utilisation, including block booking, non-standard teaching patterns, inefficient local management of rooms, lack of suitable facilities and unwillingness to re-locate (UoM 2010).

\section{S2.3. Optimise}

CE activities related to optimise are aimed at increasing system performance and efficiency by reducing resource consumption and removing waste generation from supply chains. Optimise CE activities include reducing the resource intensity of product-service systems, leverage big data, automation, remote sensing and steering to manage the products' life cycle in order to apply preventive maintenance and optimise processes, and implementing reverse logistics to facilitate products remanufacturing, upgrading and repurposing in order to recover materials (EMF 2015).

It is worth noticing that most of the environmental sustainability strategies implemented by the University of Manchester are focused on optimising organisational efficiency through a reduction in the consumption of resources, waste generation and carbon emissions (Table 1). Indeed, reducing Scope 1 (direct GHG emissions) and Scope 2 (GHG emissions from imports of electricity, heat or steam) carbon emissions (WBCSD 2001 ) by $40 \%$ for 2020 is the main driver and single quantitative KPI highlighted in the Environmental Sustainability Strategy (UoM 2016). Thus, most of the resource efficiency strategies described in the SRP, in particular those related to energy, travel, construction and purchasing, have the main purpose of reducing corporate GHG emissions. Indeed, the University of Manchester has become the first university in the world to be accredited by the Carbon Literate Organisation (2017) thanks to the $25,000+$ actions pledged by staff during the first year of launching of the 10,000 Actions programme. 
As shown in Table 1 in the paper, the university has developed energy and water saving guides for offices and labs and conducts regular inspections to identify opportunities to improve energy and water efficiency through refurbishment works, new infrastructure investments and project financing. For instance, the Revolving Green Fund (HEFCE 2017) has contributed $£ 4.4 \mathrm{~m}$ to energy saving projects (e.g. LED installations and lighting controls) leading to reduce energy consumption and GHG emissions by $46 \mathrm{GWh}$ and $22 \mathrm{kt}$, respectively (UoM 2017a). Energy saving campaigns are also run annually to raise awareness about energy saving and reduce energy consumption further. Considering a sample of 10 buildings, cost savings derived from Christmas (9 days) and Easter (4 days) closure periods account together for almost $£ 100,000$ due to $20 \%$ reduction in energy consumption (UoM 2017a).

Initiatives to support sustainable travel include the creation of personalised travel plans for staff to find the most efficient way to commute to work and frequent free intercampus bus travel. Smart drive training is also offered to staff to reduce fuel consumption, travel costs and GHG emissions. Likewise, the bike user group and a run-commute group offer support for people that wish to cycle or run to work and a walking programme (lunchtime strollers) accredited by Walking for Health (2017) is also in place.

Focusing on sustainable construction, for major Campus Masterplan (UoM 2012) construction projects, the university has appointed environmental sustainability advisors to ensure the achievement of environmental sustainability targets set in environmental sustainability project trackers (UoM 2017g). Likewise, a code of practice for design teams (UoM 2017h) has been developed to ensure environmental sustainability criteria are embedded within small construction projects. The BREEAM standard (BRE 2017) is used to certify the sustainability performance of buildings.

Finally, the University of Manchester has achieved Level 5 of the implementation of the Flexible Framework (DEFRA 2011) used to embed sustainability criteria systematically into key areas of the procurement processes. It is the first university in the UK to attain the highest achievement and leadership in the HE sector (UoM 2017d). Likewise, the university has developed a NETpositive approach to responsible procurement to work not only on reducing negative impacts from procurement activities (e.g. carbon emissions) but also to enhance positive benefits (e.g. social progress) (UoM 20170). As a result, a NETpositive Supplier Engagement Tool (NETpositive Futures 2017) is used to engage suppliers in sustainability practice. All suppliers are given access to this tool for the development of a sustainability action plan for their own business and demonstrate how they can help the university to reduce its negative externalities and enhance positive impacts. This process helps the university to reduce risks in the supply chain and enhance sustainability practice through learning.

Other optimise CE strategies implemented by the university (Table 1) include the introduction of trayless dining in all catered areas with a segregated clearing area to separate and weight waste streams. This system is instrumental to facilitate waste reduction across the university halls and it represents one of the reasons why the organisation has been awarded a one star Food Made Good award from the Sustainable Restaurant Association (SRA 2017). Several strategies related to the LCP also contribute to optimise system performance because they have the purpose of minimising resource consumption by rising awareness and engaging stakeholders in sustainability practice.

S2.4. Loop

Loop CE activities are aimed at keeping materials and products in closed-loop biological and technical cycles. It entails the refurbishing, remanufacturing and 
recycling of synthetic products and resource cascading, anaerobic digestion and extraction of bio-chemicals from organic materials (EMF 2015).

The university encourages staff and students to actively reduce (e.g. avoid purchasing unnecessary new items), reuse (e.g. share items and acquire second-hand products and equipment) and recycle (e.g. dispose of wastes responsibly by using the correct bins). When waste disposal is the only viable option (e.g. food waste), the university actively seeks to find the most sustainable waste treatment alternative (e.g. mechanical biological treatment and anaerobic digestion) to reduce the amount of waste sent to landfill.

Accordingly, the university has different waste management programmes in place that can be considered examples of loop CE actions. For instance, the furniture that is not suitable for reuse through the furniture for reuse store is collected by a local furniture recycling company (Upmcr 2017). Any item collected by UpManchester (Upmcr 2017) is responsibly dismantled in order to recycle components in different ways, which results in recovery rates exceeding 97\%. Likewise, if redundant IT equipment cannot be reused across the campus, a local recycling firm (CDL 2017) collects, sorts and manages it properly. Computer disposal Limited (CDL 2017) has the obligation to ensure they employ the best techniques available to recover products and materials. As a result, the firm is able to repair and re-sell $75 \%$ of all equipment that passes through their facility.

Finally, the university operates a campus wide recycling scheme for used toner and inkjet cartridges. These products are collected by another local firm (OfficeGreen 2017), who gives the university a rebate that is donated to local charities. A variety of recycling facilities and waste bins have been also implemented across the campus to manage over 60 waste streams (e.g. plastic bottles, cans, tins, cardboard, glass, paper, etc.). Complementarily, food waste is sent to mechanical biological treatment and anaerobic digestion in order to extract bio-chemicals and produce energy and compost.

Thanks to the implementation of these waste management schemes, the university contributes to some extend to keep materials in closed-loop systems. However, the organisation does not participate in any remanufacturing scheme (e.g. takeback systems) with suppliers. Likewise, despite the university's waste management efforts, waste generation is increasing as a consequence of the Campus Masterplan (UoM 2012) and the growing number of new students. This poses challenges to the effectiveness and efficiency of the recycling schemes currently implemented. Consequently, reinforcing and expanding internal and external recycling systems by applying strategic CE thinking is essential to overcome this challenge and improve the circularity and sustainability performance of the organisation.

\section{S2.5. Virtualise}

Virtualise CE activities refer to the dematerialisation and replacement of physical marketplaces and products by delivering virtual utilities through the use of digital technologies (EMF 2015). According to ARUP (2016), virtualisation makes it easier to exchange goods and services remotely and facilitate real-time maintenance activities, which results in resources, time and costs savings.

Only a few environmental sustainability strategies implemented by the university fall into this category (Table 1). Virtual meetings and video conferencing are encouraged in order to reduce the environmental impacts related to business travel. Likewise, IT services introduced a number of solutions, including improvements to data centres, power management, consolidation of services and heavy use of virtualisation to 
improve energy-efficiency and reduce carbon emissions. The marketplace online platform also contributes somewhat to virtualise because it facilitates product exchange between users, without the need to make use of any physical store. Similarly, trayless dining areas in residences canteens represents another example of a virtualise CE activity because it supports the partial dematerialisation of food delivery and consumption.

However, there is no evidence that the university is looking for opportunities to fully dematerialise its campus operations by acquiring services rather than purchasing products. Rather than purchasing new equipment, the organisation could benefit from accessing to performance, functionality or capability through leasing or pay-per-use contracts (Accenture 2015; Bocken et al. 2016). However, it requires a collaborative supplier engagement strategy to co-develop effective CE product-service solutions.

Accordingly, the university can extend the scope of the NETpositive supplier engagement tool (NETpositive Futures, 2017) to motivate suppliers to find ways to provide virtual CE solution to support university operations. For instance, technical spaces (labs) could benefit from the virtualisation of equipment that has a lowutilisation rate.

\section{S2.6. Exchange}

Exchange CE activities look for using best performing technologies in substitution of conventional alternatives, redesigning processes in order to develop innovative ways of doing things and choosing multifunctional products and services to deliver greater value to customers (EMF 2015). It entails therefore the use of renewable and alternative energy and materials, replacing traditional solutions with advanced technologies and replacing product-centric delivery models with innovative serviceoriented solutions (ARUP 2016).

Similarly to virtualise, only a few environmental sustainability strategies reflect the implementation of exchange CE activities and it is the result (secondary effect) from the implementation of other strategies (Table 1). For instance, the design of energyefficient and low-carbon buildings has the main purpose of optimising system performance. However, it is assumed that the university would use the best available technologies (e.g. LED lighting equipment) to ensure a reduction in the consumption of fossil resources. Therefore, all the responsible procurement strategies that look for optimising resource efficiency facilitate the implementation of exchange CE actions. It includes the development of top tips, a product label and a whole-life costing guide (UoM 2017i) to help internal procurers to choose appropriate products (e.g. the most energy-efficient) by considering the life cycle management costs.

Nevertheless, there is no evidence that the organisation is looking to rethink its business model and redesign organisational processes and operations by applying CE thinking to ensure the creation, delivery and capture of sustainable value. Rather, the environmental sustainability strategies implemented by the organisation are incremental and mostly focused on enhancing eco-efficiency, which they are not enough to maximise and support long-term organisational sustainability performance (Mendoza et al. 2017).

\section{References}

Accenture, 2015. Circular advantage: innovative business models and technologies to create value in a World without limits to growth.

Arup, 2016. The circular economy in the built environment. London, UK.

Azapagic, A. 2003. Systems approach to corporate sustainability: a general management framework. Process Safety and Environmental Protection 81: 303-316. 
Bocken, N.M.P., de Pauw, I., Bakker, C., van der Grinten, B. 2016. Product design and business model strategies for a circular economy. Journal of Industrial Product Engineering 33(5): 308-320.

BSI 8001, 2017. Framework for Implementing the Principles of the Circular Economy in Organizations - Guide. The British Standards Institution, London.

Carbon Literate Organisation, 2017. http://www.carbonliteracy.com/organisation/. Accessed: September 2017.

CDL, 2017. Computer Disposal Limited. http://www.computerdisposals.co.uk/. Accessed: October 2017.

EMF, 2015. Growth Within: a circular economy vision for a competitive Europe. Isle of Wight: Ellen MacArthur Foundation (EMF)

EMF, 2016. Intelligent assets: unlocking the circular economy potential. Isle of Wright: Ellen MacArthur Foundation (EMF).

HEFCE, 2017. Revolving Green Fund. Higher Education Funding Council for England (HEFCE). http://www.hefce.ac.uk/workprovide/rgf/. Accessed: October 2017.

ISO 14001, 2015. Environmental management systems: requirements with guidance for use. International Organisation for Standardisation, Geneva: Switzerland.

Manchester Veg People, 2017. https://www.vegpeople.org.uk/. Accessed: October 2017.

Mendoza, J.M.F., Sharmina, M., Gallego-Schmid, A., Heyes, G., Azapagic, A., 2017. Integrating backcasting and eco-design for the circular economy: the BECE framework. Journal of Industrial Ecology 21(3): 526-544.

N8, 2017. the N8 shared equipment inventory system. http://www.n8equipment.org.uk/. Accessed: October 2017.

NETpositive Futures, 2017. The NETpositive supplier engagement tool. http://netpositivefutures.co.uk/netpositive-supplier-engagement/. Accessed: October 2017.

OfficeGreen, 2017. http://www.officegreen.co.uk/. Accessed: October 2017.

Sanye-Mengual, E., Ceron-Palma, I., Oliver-Sola, J., Montero, J.I., Rieradevall, J., 2012. Environmental analysis of the logistics of agricultural products from roof top greenhouses in Mediterranean urban areas. Journal of Science and Food Agriculture 2013; 93: 100-109.

Sanyé-Mengual, E., Llorach-Masana, P., Sanjuan-Delmás, D., Oliver-Solà, J., Josa, A., Montero, J.M., Rieradevall, J., 2014. The ICTA-ICP Rooftop Greenhouse Lab (RTG-Lab): closing metabolic flows (energy, water, $\mathrm{CO}_{2}$ ) through integrated rooftop greenhouses. AESOP sustainable food planning conference. "Finding places for productive cities. Proceedings of 6th International AESOP Sustainable Food Planning Conference". Leeuwarden: p. 693-701.

Stahel, W.R., 1994. The utilization focused service economy: resource efficiency, in B. R. Allenby and D. J. Richards (eds), The greening of industrial ecosystems, National Academy Press, Washington, DC, 178-190.

SRA, 2017. Sustainable Restaurant Association. http://www.thesra.org/. Accessed: October 2017.

UoM, 2010. The University of Manchester estates strategy 2010-2020. The University of Manchester (UoM). http://documents.manchester.ac.uk/display.aspx?DoclD=8186. Accessed: September 2017.

UoM, 2012. Campus Masterplan 2012-2022. The University of Manchester (UoM). http://documents.manchester.ac.uk/display.aspx?DoclD=15305. Accessed: September 2017.

UoM, 2016. Environmental sustainability strategy: building on our heritage to create a sustainable future. The University of Manchester (UoM). http://documents.manchester.ac.uk/display.aspx?DoclD=33155\%20. Accessed: September 2017.

UoM, 2017a. Sustainable resources plan: supporting the responsible use of natural resources and materials. Environmental Sustainability Team, The University of Manchester. Manchester: UK.

UoM, 2017b. Living campus plan: a living campus where we work alongside nature and nature works alongside us. Environmental Sustainability Team, The University of Manchester. Manchester: UK.

UoM, 2017c. The marketplace. The University of Manchester (UoM). http://themarketplace.staffnet.manchester.ac.uk/. Accessed: September 2017. 
UoM, 2017d. Furniture for reuse store. The University of Manchester (UoM). http://www.estates.manchester.ac.uk/services/operationalservices/envsvcs/waste/furniturere cycling/\#d.en.287713. Accessed: September 2017.

UoM, 2017e. IT reuse centre. The University of Manchester (UoM). http://www.itservices.manchester.ac.uk/aboutus/sustainability/disposal/. $\quad$ Accessed: September 2017.

UoM 2017f. Sustainability in catered halls. The University of Manchester (UoM). http://www.accommodation.manchester.ac.uk/ouraccommodation/sustainabilityincateredhall s/. Accessed: September 2017.

Uo $\bar{M}$ 2017g. Environmental sustainability project tracker. The University of Manchester (UoM). http://documents. manchester.ac.uk/display.aspx?DoclD=33441\%20. Accessed: September 2017.

UoM 2017h. Code of practice for design teams. The University of Manchester (UoM). http://www.estates.manchester.ac.uk/media/services/estatesandfacilities/policiesandprocedu res/EPM\%20PM7\%20-\%20Code\%20of\%20Practice\%20for\%20Design\%20Teams.pdf. Accessed: September 2017.

UoM 2017i. Responsible procurement for internal buyers. The University of Manchester (UoM). http://www.procurement.manchester.ac.uk/procurementexcellence/responsibleprocurement/responsibleprocurementbuyersquide/. Accessed: September 2017.

Upmcr, 2017. UPmanchester. http://upmanchester.com/. Accessed: October 2017.

Walking for health, 2017. Supporting you to get active and stay active. https://www.walkingforhealth.org.uk/. Accessed: October 2017.

WBCSD, 2001. The Greenhouse Gas Protocol: a corporate accounting and reporting standard. World Business Council for Sustainable Development (WBCSD): Switzerland. 